\title{
Beyond equilibrium climate sensitivity
}

\section{Review Article}

Author(s):

Knutti, Reto; Rugenstein, Maria A.A.; Hegerl, Gabriele C.

Publication date:

2017-10-01

Permanent link:

https://doi.org/10.3929/ethz-b-000197761

Rights / license:

In Copyright - Non-Commercial Use Permitted

\section{Originally published in:}

Nature Geoscience 10(10), https://doi.org/10.1038/NGEO3017 
Beyond equilibrium climate sensitivity

Reto Knutti* (1,2), Maria A. A. Rugenstein (1) and Gabriele C. Hegerl (3)

(1) Institute for Atmospheric and Climate Science, ETH Zurich, $\mathrm{CH}-8092$ Zurich, Switzerland

(2) National Center for Atmospheric Research, Boulder, Colorado, USA

(3) School of Geosciences, University of Edinburgh, Edinburgh, EH9 3JW, UK

Nature Geoscience, 2017, http://dx.doi.org/10.1038/ngeo3017

*Correspondence to: reto.knutti@env.ethz.ch

Equilibrium climate sensitivity characterizes the Earth' long-term global temperature response to an increased atmospheric carbon dioxide concentration. It has reached almost iconic status as the single number that describes how severe climate change will be. The consensus 'likely' range for climate sensitivity of $1.5-4.5^{\circ} \mathrm{C}$ today is the same as given by Jule Charney in 1979 , but is now based on quantitative evidence from across the climate system, and through climate history. The quest to constrain climate sensitivity has revealed important insights into the timescales of the climate system response, natural variability, limitations in observations and climate models, but also concerns about the simple concepts underlying climate sensitivity and radiative forcing, which open avenues to better understand and constrain the climate response to forcing. Estimates of the transient climate response are better constrained by observed warming and are more relevant for predicting warming over the next decades. Newer metrics relating global warming directly to the total emitted $\mathrm{CO}_{2}$ show that in order to keep warming to within $2^{\circ} \mathrm{C}$, future $\mathrm{CO}_{2}$ emissions have to remain strongly limited, irrespective of climate sensitivity being at the high or low end.

If we increase the amount of $\mathrm{CO}_{2}$ in the Earth's atmosphere and wait for climate to respond, how much warmer would surface temperatures eventually get? What seems like a simple but important question to ask given current and projected human-induced $\mathrm{CO}_{2}$ emissions, is an issue that scientists have struggled with since the first rough estimates were made more than a century ago ${ }^{1,2}$. To answer that question, starting in the 1960s, scientists have used energy balance arguments combined with observed changes in the global energy budget, evaluated comprehensive climate models against observations, and analyzed the relationship between external forcing and climate change over different climate states in the past (see Methods for a list of early publications). The idea of using those different lines of evidence has not changed, but progress in simulating climate, a longer and more accurate observed record of past warming, and better constrained paleoclimate reconstructions now offer more possibilities to evaluate and constrain models. However, recent research has pointed out previously unknown limitations in some of the concepts and assumptions underlying a single constant climate sensitivity ${ }^{3}$. While publications have appeared using various methods, arguably the most important conceptual recent insights is that feedbacks change with equilibration time, an insight that is based on studies in comprehensive climate models. Other recent insights show that the treatment of observations is important ${ }^{4}$.

Knowing, to first order, how the global climate will warm in response to increased $\mathrm{CO}_{2}$ is critical: for unabated emissions, it is the difference between a hot and an extremely hot future. The value of halving the uncertainty in that projection may be in the trillions of dollars ${ }^{5}$. Here we update an earlier review $^{6}$ and report recent progress in this area. We discuss limitations, highlight the implications for climate science and policy, discuss new metrics that relate the climate response directly to emissions, and propose avenues for future research. 


\section{Introduction}

The climate system response to changes in the Earth's radiative balance depends fundamentally on the timescale considered. The initial transient response over several decades is characterized by the transient climate response (TCR), defined as the global mean surface warming at the time of doubling of $\mathrm{CO}_{2}$ in an idealized $1 \%$ /year $\mathrm{CO}_{2}$ increase experiment, but is more generally quantifying warming in response to a changing forcing prior to the deep ocean being in equilibrium with the forcing (see Methods). Based on state of the art climate models, and instrumentally recorded warming in response to $\mathrm{CO}_{2}$ and other anthropogenic and natural forcings, the transient climate response has been assessed in the Intergovernmental Panel on Climate Change Fifth Assessment Report (IPCC AR5) to be 'likely' ( $>66 \%$ probability) in the range of 1.0 to $2.5^{\circ} \mathrm{C}$ (Figure 1$)^{7}$. In contrast, the equilibrium climate sensitivity (ECS) is defined as the warming for doubling $\mathrm{CO}_{2}$ in the atmosphere relative to preindustrial climate, after the climate reached its new equilibrium, taking into account changes in water vapor, lapse rate, clouds and surface albedo. It takes thousands of years for the ocean to reach a new equilibrium. By that time, long-term Earth system feedbacks, such as changes in ice sheets and vegetation, and the feedbacks between climate and biogeochemical cycles ${ }^{3,6,8}$ will further affect climate, but such feedbacks are not included in ECS because they are fixed in these model simulations. Despite not directly predicting actual warming, ECS has become an almost iconic number to quantify the seriousness of anthropogenic warming. This is a consequence of its historical legacy, the simplicity of its definition, its apparently convenient relation to radiative forcing, and because many impacts to first order scale with global mean surface temperature. The estimated range of ECS has not changed much despite massive research efforts. It is assessed in IPCC to be 'likely' in the range $1.5-4.5^{\circ} \mathrm{C}$ (Figures 2 and 3), which is the same range given by Charney in 1979 $\left(\right.$ ref. ${ }^{9}$ ). The question is legitimate: Have we made no progress on estimating climate sensitivity?

\section{Constraints from the instrumental record and present day variability}

ECS and TCR cannot be measured directly, but in principle can be estimated from a) quantifying feedbacks, ECS, and TCR in comprehensive climate models, b) potentially constraining models by their representation of present day mean climate and variability, c) analysis of the post-industrial observed warming of the ocean and atmosphere in response to forcing, d) the short-term climate response to forcing, such as volcanic eruptions, or to interannual temperature variations, and e) paleoclimate records, e.g., the cooling at the Last Glacial Maximum or the warming during earlier warm periods. A summary of estimates are shown in Figure 1, 2 and 3.

The use of the recent warming as a constraint is attractive, as greenhouse gases have 'likely' caused $0.5^{\circ} \mathrm{C}$ to $1.3^{\circ} \mathrm{C}$ of warming (>66\% probability) over the period $1951-2010$, while there is also 'very likely' a human contribution to upper ocean warming ${ }^{7}$. However, estimating ECS and TCR from the instrumental record requires a conceptual or physical mode ${ }^{10}$. In the simplest form, the difference between the radiative forcing $F$ today and the resulting change in radiation $\lambda T$ resulting from the surface warming $T$ needs to be equal to the net energy uptake $Q$ of the system: $Q=F-\lambda T$ (see refs. 3,6 for details). Over $90 \%$ of the excess energy $Q$ is taken up by the ocean, so $Q$ is usually taken equal to the global ocean heat uptake. The inverse of the climate feedback parameter $\lambda$ is the estimated climate sensitivity parameter in ${ }^{\circ} \mathrm{C} / \mathrm{Wm}^{-2}$, which is converted to ECS by multiplying it with the forcing for $2 \times \mathrm{CO}_{2}$ (about 3.7 $\mathrm{Wm}^{-2}$ ). The ratio of $\mathrm{T} / \mathrm{F}$ estimates $\mathrm{TCR}^{11}$. In principle, observations of the surface warming $T$ and ocean heat uptake $Q$, combined with a model-based estimate of the forcing $F$ therefore determine ECS and TCR. Other approaches evaluate which values of ECS or TCR in models best reproduce observed patterns in space and time of surface and ocean warming. Related detection and attribution approaches separate the response to greenhouse gases from that to other drivers and variability to estimate TCR and ECS (see Methods for details and references). In all of 
these methods, uncertainties in forcing (particularly from aerosols) are a key driver of the overall uncertainty: energy budget estimates use the overall magnitude of forcing F directly, while in pattern-based methods the uncertainty in the space-time patterns of forcing limits confidence.

Many recent estimates of ECS based on the historic warming yield a reduced probability for large ECS, reduced lower bounds, and most likely values near $2^{\circ} \mathrm{C}$. This is reflected in the shift of the IPCC assessed lower limit of the 'likely' range from $2^{\circ} \mathrm{C}$ in AR4 to $1.5^{\circ} \mathrm{C}$ in AR5 (see Figure 2), and supports the statement that ECS is 'very unlikely' greater than $6^{\circ} \mathrm{C}$. Reasons for a tightened range of ECS from historical climate change are longer records measured at (nominally or actually) higher precision and with better coverage particularly in the ocean, such that the forced signal emerges more clearly from variability ${ }^{12,13}$, and a larger total radiative forcing (as a result of increasing GHG concentrations and a smaller, less negative, aerosol forcing ${ }^{7,14}$ ). Warming rates have been somewhat lower between about 1998 and 2013 compared to decades before ${ }^{15}$, which tightens some estimates ${ }^{16}$ but not others ${ }^{17}$. Following some criticism ${ }^{18,19}$ recent estimates generally use multiple prior assumptions in order to evaluate to what extent results hinge on those assumptions ${ }^{20}$; some use 'objective Bayesian methods ${ }^{\prime 18}$. Results illustrate that prior assumptions particularly matter for the likelihood of high ECS.

Uncertainty ranges in individual studies are affected by the often simple models used (see limitations), and by assumptions made, including those about forcing and about internally generated variability ${ }^{21}$. Recently it has also been recognized that results that compare model surface air temperature with observed sea surface temperature over ocean, together with biases due to uncaptured warming in some regions, may underestimate equilibrium and transient warming ${ }^{4,22}$. Often labeled as 'observational', these methods do rely on models: both to provide forcing estimates, such as aerosol forcing, and to link forcing to climate response through energy balance models. Hence, observational estimates are complementary to methods using comprehensive models, but have their own uncertainties.

Since TCR is determined by the ratio of observed warming rate to forcing, the observed warming constrains TCR better than ECS, as evident by the closer agreement of ranges arising from TCR estimates between each other and with those from climate models (Figure 1).

\section{Constraints from climatology, feedback analysis and comprehensive models}

The values of ECS and TCR from comprehensive fully coupled climate models, which embed our best understanding of the relevant feedbacks, are one line of evidence and provide a plausible range that is consistent with a variety of observations. With the advance of perturbed physics ensembles (i.e., one climate model run with multiple parameter sets exploring uncertainty more fully) and the Coupled Model Intercomparison Project (CMIP) multi model ensembles ${ }^{23}$, studies on 'emergent constraints' became another prominent and complementary line of argument. The idea is to downweight models with large biases, or to find well-understood relationships between an observable quantity in the present day and future projections, and thus use observations to constrain the range of models. In many cases, correlations of observable quantities to TCR and ECS are weak, but some studies find relationships between atmospheric mixing, humidity or radiative fluxes and ECS (see Methods for details and references). Open issues are the choices of metrics for emergent constraints or weighting, and the fact that many models share code or parameterization concepts and as a result are not independent. There is strong evidence, however, that a credible representation of the mean climate and variability is difficult to achieve in current models with equilibrium climate sensitivities below $2^{\circ} \mathrm{C}$, and current GCMs favour sensitivities near $3^{\circ} \mathrm{C}$ or above (see Methods). This is consistent with the argument that water vapor and lapse rate combined would almost double the black body response to near $2^{\circ} \mathrm{C}$, and with the surface albedo feedback being positive, a strongly negative cloud feedback (or a large part of the recent warming being of natural 
origin) would be needed to explain a low sensitivity ${ }^{24,25}$, which is not supported by observations and attribution studies ${ }^{7}$. Recent progress in estimating cloud feedbacks therefore leads to a "null hypothesis" for ECS above $3^{\circ} \mathrm{C}$ based on the robustly quantified feedbacks ${ }^{26-29}$. Few studies have used climatological mean constraints ${ }^{30}$ or decadal prediction bias tendencies to constrain TCR ${ }^{31}$. Overall, the raw range of ECS values in CMIP5 as well as emergent constraints from selected observations and CMIP5, and analysis of feedbacks favour the upper half of the IPCC ECS range (Figure 3).

\section{Constraints based on paleoclimate}

Constraints on ECS also arise from paleoclimate studies, which relate long-term temperature responses to changes in the planet's energy balance and which have made significant progress in recent years (see Methods, reflected in several studies shown in Figure 3). Estimates from paleoclimate record a response that is often close to equilibrium, but are affected by uncertainty in reconstructed past climate and forcing, both of which are inferred from indirect evidence that may not be spatially representative or may be responding to multiple factors, uncertainties that are difficult to quantify. The majority of estimates arise from the Last Glacial Maximum (LGM) or the last few glacial cycles. Most of that period was substantially colder than present, driven by the albedo effect of large ice sheets, reduced greenhouse gases, dust forcing, changed vegetation cover and different orbital forcing. If climate models include these changes, reconstructed cooler sea surface temperatures (SST) in the tropics, and colder global temperatures are reproduced reasonably well, although with spatial uncertainty. Most but not all estimates of ECS that are based on model-data fit of these reconstructed ranges for models with different values of ECS support the range of 1.5 to $4.5^{\circ} \mathrm{C}$ and yield ECS higher than $5-6^{\circ} \mathrm{C}$ unlikely (see Figure 3, refs. ${ }^{7,8}$ and Methods). Uncertainties in reconstructed temperatures and forcing become larger when moving into the more distant past.

Paleoclimate evidence and modelling suggests that Earth system feedbacks, such as the growth of ice sheets in response to cooling during the LGM, enhance the response to a long-term change in $\mathrm{CO}_{2}$, acting as further long-term feedback, as do vegetation changes, and changes in dust. In the studies shown in Figure 3 these feedbacks are generally treated as a forcing and not part of ECS. However, when considering predictions into the far future, Earth system feedbacks will come into play and will likely enhance warming anticipated from ECS on timescales of centuries to millennia.

\section{Discrepancy and lack of progress?}

A striking feature of Figures 2 and 3 is that evidence from climate modelling favors values of ECS in the upper part of the 'likely' range, while many recent studies based on instrumentally recorded warming, and some from palaeoclimate, favor values in the lower part of the range. Since each line of evidence is affected by different uncertainties, their uncertainty ranges should encompass the 'true value' but do not need to be identical. It is however important to understand the differences, as discussed in the following sections. In principle, the consistency of information across the partially independent lines of evidence should further reduce uncertainty in ECS, as illustrated in Figure 2 for a few published attempts using combined constraints.

As a result of some recent low ECS estimates, the central 'likely' range assessed in IPCC ${ }^{7}$ was wider than the $2-4.5^{\circ} \mathrm{C}$ range in the previous report, and no best estimate was given. However, the outer boundaries were stronger constrained than before, rendering it 'extremely unlikely' $(<5 \%)$ that ECS is less than $1^{\circ} \mathrm{C}$ (high confidence), and 'very unlikely' $(<10 \%)$ that it is greater than $6^{\circ} \mathrm{C}$ (medium confidence), based on the combined evidence.

TCR was assessed in IPCC ${ }^{7}$ as being 'likely' in the range $1^{\circ} \mathrm{C}$ to $2.5^{\circ} \mathrm{C}$ (close to the estimated 5 to $95 \%$ range of the CMIP5, $1.2^{\circ} \mathrm{C}$ to $\left.2.4^{\circ} \mathrm{C}\right)$, and 'extremely unlikely' $(<5 \%)$ greater than $3^{\circ} \mathrm{C}$. For TCR, a few 
climate models with the largest TCR are outside the 5-95\% range estimates derived from the instrumentally recorded warming, but some of this may be affected by the treatment of observations (see below and Methods) and variability. In general, the GCM ranges and those from the observed warming are more consistent for TCR than ECS.

\section{Limitations and future research avenues}

For comprehensive climate models, the biggest concern is that they share some limitations (e.g., finite resolution, parameterized convection, etc.) and are evaluated against the same imperfect observations, so they may be biased in a similar way. Clouds have long been, and still are, the largest uncertain feedback ${ }^{7,32,33}$, in particular in the stratocumulus subsidence regions over tropical oceans, and their effect on the shortwave radiation budget. It will take decades before clouds can actually be resolved in climate change simulations using global models because of the required resolution, even if computing capacity continues to increase as it has. Climatological fields and warming over the $20^{\text {th }}$ century are taken as a constraint for model evaluation explicitly in many institutions, but models are not tuned to specific values of ECS. Whether there is a tendency for model developers to keep ECS in an "acceptable" range is unclear. Given the skewness of ECS from feedback theory, and the fact that it is challenging to produce a substantially negative cloud feedback, it is much easier to produce a model with good performance on mean climate and a climate sensitivity above the IPCC range than one below. Despite all limitations in models, the range of ECS across 'best effort' models has been stable at around $2-5^{\circ} \mathrm{C}$ for decades, and fundamental understanding of feedbacks and climatological mean constraints are very difficult to reconcile with a very low ECS (see Methods for details).

Evidence from observed climate change is also uncertain. Observational uncertainty remains, even for the most recent decades, and like-with-like comparison of data is important ${ }^{4,22}$, and natural variability superimposes on the forced trend and causes uncertainty even for multi-decadal trends ${ }^{12,13}$. This is usually addressed by using internal variability estimates, although in some cases quite simple ones, or by including modes of variability as explanatory variables or covariates. However, it is not always clear to what extent such modes partly reflect the response to forcing - the Atlantic Multidecadal Oscillation (AMO), for example, may partly be a response to volcanic and aerosol forcing. Further, forcing is a key uncertainty: While some studies argue for a smaller (less negative) aerosol forcing ${ }^{14}$, others argue for a larger aerosol radiative forcing uncertainty than used in IPCC ${ }^{34}$, both of which would affect ECS estimates. The magnitude of the preindustrial aerosol baseline is also important but hard to constrain ${ }^{35}$.

The most pressing issue, however, is the growing concern that assuming a single constant global feedback parameter $\lambda$ is unrealistic. Doing so would imply that the equilibrium climate sensitivity for $\mathrm{CO}_{2}$ doubling in a fully coupled model is the same as the effective climate sensitivity extrapolated from a transient simulation ${ }^{36}$, yet many simple models interpreting the observed record are just assuming such a constant feedback. It also neglects differences in the temperature response to forcing that are not captured by a forcing efficacy. Feedbacks, however, are spatially heterogeneous. They are not necessarily linear with increasing temperature ${ }^{37}$, and the total response depends strongly on the spatial pattern of warming ${ }^{38-42}$, which changes over time. Despite characterizing equilibrium, ECS therefore depends just like $\mathrm{TCR}^{43,44}$ strongly on the ocean heat uptake and circulation response, which modifies the pattern of warming. It was pointed out long ago that the transient feedback may be a poor estimate of $\mathrm{ECS}^{36,45,46}$ but recent studies provide stronger evidence for substantial state and time dependence of the global feedback both for just $\mathrm{CO}_{2}$ forcing and for the historical period ${ }^{3,38,41,47-62}$. As one example, Figure 4 a shows the estimated temperature response and radiative imbalance from the NCAR CESM model resulting from a step increase to $4 \times \mathrm{CO}_{2}$. The initial years are simulated many times for different initial conditions to get a precise estimate of the forced 
response. The evolution in CESM clearly deviates from a straight line implied by a constant feedback. The slope of the regression $\lambda$ is also not constant for most other CMIP5 models due to both shortterm atmospheric and oceanic adjustments, and due to feedbacks and warming patterns changing over time.

Other concerns are that feedbacks may not be additive, and the climate response depends on the type and magnitude of the forcing ${ }^{37,61,63-80}$. Additional difficulties arise in separating forcings and feedbacks ${ }^{27,80,81}$, and defining appropriate forcings that account for short term atmospheric and oceanic adjustments ${ }^{82-91}$. The slope of the regression as a measure of the feedback may further depend on the climate base state, and the particular observed realization of natural variability in the real world. Most of these effects sketched in Figure $4 b$ that potentially affect the total feedback cannot be quantified robustly at this point. Current understanding however indicates that estimates of ECS based on the instrumental warming and a constant $\lambda$ model are biased low, as indicated by the curvatures in Figure 4a. The delayed Eastern tropical Pacific and Southern ocean warming in the observed historical period, combined with feedbacks changing as the warming pattern changes, plus the composition of the historical forcing and an underestimation of the observed warming (see Methods), imply that ECS estimates assuming constant $\lambda$ are likely underestimated ${ }^{3,4,54,59-62}$. In principle, climate models can be used to study how feedbacks vary, but different models show different changes in $\lambda$, so the bias in the ECS estimated from historical data when assuming constant $\lambda$ may be anywhere from near zero to about a factor of two $0^{54,59,60,65,68,92}$. Accounting for changes in feedbacks and the observation issues largely resolve the apparent discrepancies between the estimates from the observed warming and those from comprehensive models.

Testing if simple methods work by estimating known ECS and TCR from complex models ${ }^{93}$ may help improve energy balance models ${ }^{50,51}$. Now that the observations are longer and less uncertain, and the warming signal becomes stronger relative to variability, the observations provide much stronger constraints even on ECS. This is why limitations in the model structure become more important, and these can potentially be understood when such methods are evaluated in perfect model tests.

\section{Conclusions and implications for research and policy}

The goal of this review is not to come up with a single number or range for ECS based on a rigorous mathematical framework. Indeed that is very challenging given the various methods, assumptions, datasets and models used in all the studies. Our overall assessment of ECS and TCR is broadly consistent with IPCC ${ }^{7}$ but concerns arise about estimates of ECS from the historical period that assume constant feedbacks, raising serious questions to what extent ECS values less than $2^{\circ} \mathrm{C}$ are consistent with current physical understanding of climate feedbacks. A value of around $3^{\circ} \mathrm{C}$ is most likely given the combined evidence and the recognition that feedbacks change over time. A rough sketch of the three main constraints as probability density functions (PDFs) is given in Figure 5a (see Methods for details). For uniform priors and independent constraints, the PDFs could simply be multiplied ${ }^{94,95}$. However, combining multiple lines of evidence in a formal statistical way is difficult: independence is difficult to establish, joint PDFs would need to be combined, and uncertainties that are poorly quantified or neglected will eventually render the result unreliable ${ }^{6}$. The product here results in a combined constraint that is very narrow and likely overconfident. When the individual PDFs of GCMs and paleoclimate are, just for illustration (Figure 5b), inflated in their lower and upper bounds to account for potential structural problems, state dependent feedbacks and dependency across the lines of evidence, and in addition the mismatch between the historically inferred and future sensitivity $4,59,60$ is accounted for by extending the historical PDF upward (see Methods), the combined evidence from the three PDFs would still yield a rather narrow range constraining ECS to 2- 
$4^{\circ} \mathrm{C}$ with a most likely value near $3^{\circ} \mathrm{C}$. However, this toy model does not replace a full assessment. Indeed the single biggest future challenge, and opportunity at the same time, is to combine the different lines of evidence, taking into account the dependence between them and avoid overconfidence due to missing uncertainty in individual lines of evidence ${ }^{32}$.

The IPCC assessed ranges of ECS and TCR are supported by multiple lines of evidence, each based on many published studies that account for uncertainty to varying extents, and are combined by an expert assessment accounting for overall uncertainty. This is in sharp contrast to Charney in 1979 (ref. ${ }^{9}$ ), who quoted the same ECS range, but whose argument was based on physical intuition and results from only two early climate models, which by any standards today would be considered inadequate.

Uncertainties in projections may not decrease quickly in the future ${ }^{96}$, but there are promising avenues for future research. The greenhouse gas induced warming will continue to strengthen the constraint on TCR and ECS as warming continues ${ }^{97,98}$, but accounting for variations in feedbacks over time and variations in feedbacks across forcings remains a major challenge. Model-based estimates of ECS and TCR now more fully account for model uncertainty, and much hope lies in the use of more detailed process understanding, combined with better observations and higher computational capacity, to better quantify individual feedbacks. Emergent constraints provide another avenue to further reduce uncertainty ${ }^{99}$. Super-parameterizations and large eddy simulations offer new opportunities to better represent clouds ${ }^{100,101}$. Using GCM ensembles for paleoclimate studies and for the historical period allow to better use spatial information, to estimate how past warming or cooling relates future warming as feedbacks vary over time ${ }^{102}$. The challenge then is that climate model information (and potential biases) are part of each line of evidence, making them less independent.

When a PDF of ECS or TCR is required for impact studies or economic models, we recommend selecting carefully among the published estimates, using those that include recent data when the constraints become stronger, and add further structural uncertainty that often is not considered in individual estimates. There is no reason to give all published PDFs equal weight. A preferable option is to use an overall range based on an assessment combining the evidence ${ }^{32}$. Cost-benefit studies are particularly sensitive to assumptions about the tails of ECS and TCR PDFs ${ }^{103}$.

A pressing issue is to eliminate the confusion between different concepts of climate sensitivity and to agree on a target quantity that most meaningfully quantifies the climate response to $\mathrm{CO}_{2}$, and to investigate whether thinking about it as a universal constant climate system property is meaningful at all. Almost all GCMs, and studies based on the instrumental period in fact estimate an effective sensitivity (the measure of the feedbacks over some past or near future period, extrapolated to equilibrium assuming in most cases constant feedbacks) rather than a true equilibrium. Paleoclimate estimates are near equilibrium but have to account for Earth System feedbacks. Given the huge computational costs and large differences in model behavior when approaching the equilibrium, we need to rethink the timescale for which climate sensitivity is defined in the most helpful way. We also need to better quantify how the different quantities - TCR, effective climate sensitivity, near equilibrium (e.g., after 300 years of stable forcing, or within $0.5 \mathrm{~W} / \mathrm{m}^{2}$ global imbalance) and true ECS - are related ${ }^{59}$, and which of these many quantities is most relevant for which question.

Knowing a fully equilibrated response is of limited value for near term projections and mitigation decisions ${ }^{104}$ and the social anchoring on $\mathrm{ECS}^{105}$ detracts from what science can in fact say about future warming. The TCR is more relevant for predicting climate change over the next century, it relates more clearly to the social cost of carbon ${ }^{106}$, is better constrained by instrumentally recorded climate change, and the emerging warming signal (combined with the well-known $\mathrm{CO}_{2}$ forcing 
becoming increasingly dominant over the declining aerosol forcing) is likely to constrain it further and faster ${ }^{98,107}$. Some earlier studies indicated that the CMIP5 long term temperature projections may be slightly biased high ${ }^{108,109}$ while others suggested they may be slightly biased low ${ }^{110,111}$. But given the most recent data, knowledge of coverage issues, and the difficulties of calibrating TCR based on past trends (see above), we argue there is no evidence that the CMIP5 projections are biased. The overall assessed temperature range in IPCC is broader than the CMIP model range ${ }^{7,112}$. In terms of policy, and from a risk perspective, it is important to know the upper bound on TCR and ECS when limiting warming to $2^{\circ} \mathrm{C}$ or $1.5^{\circ} \mathrm{C}$ with high probability ${ }^{113}$.

The arguably most powerful recent new insight for mitigation decision is that transient warming is nearly proportional to the total emitted carbon. This concept is captured in a parameter called the transient climate response to cumulative carbon emissions (TCRE), and is another central emerging climate system property. It is defined as the global temperature change for $1000 \mathrm{GtC}$ of carbon emissions. The TCRE is estimated by IPCC to 'likely' ( $>66 \%$ probability) be in the range $0.8-2.5^{\circ} \mathrm{C}$ per $1000 \mathrm{GtC}\left(1 \mathrm{GtC}=10^{15}\right.$ grams of carbon $\left.=3.67 \mathrm{GtCO}_{2}\right)$ for emissions up to about $2000 \mathrm{GtC}$ and until temperatures peak (see Methods). Even though the limits of the TCRE concept remain to be fully understood, TRCE relates climate targets more directly to emission reductions needed than ECS ${ }^{114}$ : any temperature target implies a limit on the cumulative emission budget. To 'likely' remain below $2^{\circ} \mathrm{C}$, about two thirds of the total 'permitted' emissions have been emitted already, ${ }^{7,15}$. The remaining budget at current emissions would last only about 30 years, and less for $1.5^{\circ} \mathrm{C}$ target or if a more realistic preindustrial temperature baseline is chosen ${ }^{116,117}$. If TCR and ECS were lower than currently assessed (for which there is little evidence), that would allow for only slightly less aggressive mitigation, but not eliminate the need for decarbonization of society. Mitigating non- $\mathrm{CO}_{2}$ forcings also offers little flexibility in achieving the $2^{\circ} \mathrm{C}$ goal ${ }^{118}$. Reducing the uncertainty range of the allowable cumulative carbon budget is more important for mitigation decisions than knowing ECS. But even more pressing are the debates about fair contributions for each country in reducing emissions, helping others to do so, and adapt ${ }^{119-121}$, and the lack of willingness to step up and lead the pack ${ }^{122}$. Current and proposed mitigation efforts are inconsistent with what would be required for the 1.5 or $2^{\circ} \mathrm{C}$ target ${ }^{114,123}$, and even these are politically difficult. Better quantifying climate feedbacks and climate sensitivity is not necessary for eliminating those roadblocks. 


\section{Acknowledgements}

R.K. was supported by NCAR and the Regional and Global Climate Modeling Program (RGCM) of the US. Department of Energy, Office of Science (BER), Cooperative Agreement DE-FC02-97ER62402. The National Center for Atmospheric Research is sponsored by the National Science Foundation. G.H. was supported by the ERC funded project TITAN (EC-320691), by the Wolfson Foundation and the Royal Society as a Royal Society Wolfson Research Merit Award (WM130060) holder, and by the NERCfunded SMURPHS project. We acknowledge the World Climate Research Programme's Working Group on Coupled Modelling, which is responsible for CMIP, and we thank the climate modeling groups for producing and making available their model output. For CMIP the U.S. Department of Energy's Program for Climate Model Diagnosis and Intercomparison provides coordinating support and led development of software infrastructure in partnership with the Global Organization for Earth System Science Portals.

Author Information:

Correspondence and requests for materials should be addressed to R.K. (reto.knutti@env.ethz.ch).

Author contributions:

All authors jointly wrote the review. M.R. produced Figures 1-4. R.K. produced Figure 5.

Competing financial interests:

The authors declare no competing financial interests. 


\section{Methods}

After some early estimates with varying definitions of $\mathrm{ECS}^{1,2,124-126}$, scientists started in the 1960 s to use energy balance arguments combined with observed changes in the global energy budget since the beginning of the industrialization ${ }^{127-132}$, to use more or less comprehensive climate models to study feedback processes and evaluate them against observations ${ }^{133-139}$ and to study different climate states in the past ${ }^{140-142}$, all in the hope to constrain future climate change. The following sections provide definitions, details about the methods using in most common categories, references, and discuss selected results and limitations of more recent studies. The discussion is focused on ECS but many studies provide also estimated TCR based on the same or similar methods. Some studies are reviews, combine methods or other do not easily fit into any of the categories below $^{6,143-147}$.

\section{Definitions and timescales}

Radiative forcing is defined as the changes in the radiation balance at the tropopause as a result of external drivers like greenhouse gases and aerosols before the surface responds, but different definitions exist for different purposes ${ }^{7,86,87,91}$ and the forcing is not easily separable from the response in the real world and even the models. The warming following a step change in radiative forcing is characterized by multiple timescales, which are related to the climate model feedbacks ${ }^{3,60,93,148-160}$ : a large fraction of the response occurs within years to few decades $(40-50 \%$ after a decade, $60-70 \%$ after a century). The transient climate response (TCR), defined as the global mean surface warming at a doubling of $\mathrm{CO}_{2}$ in an idealized $1 \% /$ year $\mathrm{CO}_{2}$ increase experiment of a climate models, characterizes the temperature response on timescales of decades to a century. It agrees well with the transient climate sensitivity concept and hence captures the warming in response to forcing before the deep ocean has equilibrated ${ }^{161}$. For predictions over the next several decades TCR is therefore the most relevant predictor ${ }^{48,112,162-164}$. The ocean-atmosphere system only approaches equilibrium with a radiative forcing (about $90 \%$ after 1000 years) when the deep ocean is close to equilibrium as well. The timescales of equilibration (and therefore the ratio of TCR to ECS) depend on ocean mixing and ECS 3,6,11,128,130,136,148,150,162,165-172. Equilibrium climate sensitivity (ECS) is defined as the equilibrium warming after doubling $\mathrm{CO}_{2}$ in the atmosphere, but disregarding Earth system feedbacks. The radiative forcing for a doubling of $\mathrm{CO}_{2}$ is about $3.7 \mathrm{~W} / \mathrm{m}^{2}$ (ref. ${ }^{173}$ ). When estimating an effective climate sensitivity through linear regression ${ }^{36}$, CMIP5 models suggest that 3.4 $\mathrm{W} / \mathrm{m}^{2}$ is a more representative value (ref. ${ }^{7, T a b l e} 9.5$ ). But because of atmospheric and oceanic adjustment processes on various timescales and changing feedbacks there is no consensus on what value to use for radiative forcing in simple models, and by which method to estimate it for different applications $\mathrm{s}^{7,84,86,91,174}$. Further difficulties arise in defining forcing for species other than $\mathrm{CO}_{2}$. In state of the art climate models, the warming to equilibrium beyond present day, but based on present day atmospheric concentrations, ranges between about $0.6^{\circ} \mathrm{C}$ and $2.5^{\circ} \mathrm{C}$ (refs. ${ }^{7,93}$ ).

\section{Constraints from feedback analysis}

IPCC AR5 estimated that the combined lapse rate and water feedback is 'extremely likely' (>95\%) positive, and cloud and albedo feedbacks are 'likely' positive. Together, this leads to 'very high confidence' that these feedbacks amplify the warming of about $1.1^{\circ} \mathrm{C}$ that would occur without feedbacks. Recent studies based on individual feedback analysis suggest that ECS should be near or above $3^{\circ} \mathrm{C}$ based on well quantified feedbacks, with additional uncertain cloud feedbacks either increasing or decreasing that value ${ }^{26-28}$. Inferring the uncertainty in ECS, the inverse of the total feedback, is challenging in particular when the total feedbacks are strong, and results in an poorly constrained upper bound ${ }^{146,175-179}$. Non-constant feedback (see the Limitations section in the main 
text) are another strong argument that constraining feedbacks might be more helpful than constraining $\mathrm{ECS}^{180}$. A caveat on analyzing individual feedbacks is that there are covariances between feedbacks.

\section{Constraints from the observed transient warming}

A variety of mostly energy balance models and statistical methods have estimated ECS and TCR based on the energy balance $Q=F-\lambda T$, where $F$ is the calculated total radiative forcing, $Q$ is the observed planetary heat uptake, $\lambda$ is the climate feedback parameter and $T$ is the observed total surface warming from all forcings. These methods either infer ECS or TCR from a present day warming in response to forcing relative to an earlier baseline period, or fit simple models to the observations while varying sensitivity, ocean heat uptake and scan forcing uncertainty in order to determine what values of these parameters combined yield consistent simulations of the historical record ${ }^{11,12,16,18,21,44,169,181-213}$, or fitting other statistical models to the observed warming ${ }^{214-216}$. Results from these methods are affected by assumptions such as a constant feedback parameter, and also need a realistic model for internal climate variability. A few more complex models have also been constrained with both past trends and climatology 217,218 .

Detection and attribution methods are based on the physical mechanisms of greenhouse gas forcing causing a characteristic space-time pattern of warming, e.g., more warming over land than ocean, delays in the response to radiative forcing driven by the thermal inertia of the ocean, cooling from aerosols being concentrated in certain regions, as well as a vertical pattern of warming in the troposphere and cooling in the stratosphere. They relate only the greenhouse gas attributable warming to the greenhouse gas forcing to estimate mostly TCR (or equivalently near term warming in a scenario) $)^{17,108,109,163,219-224}$. Thereby they circumvent the large uncertainty in the total radiative forcing due to the aerosols, but are affected by uncertainty in the model-simulated fingerprints that are matched to observations, and in the assumption that forced responses approximately superimpose linearly. A detailed discussion of each study is beyond the scope of this review, but previous reviews and assessments ${ }^{6,7,225}$ review most individual studies and find an overall 'likely' ( $>66 \%$ probability) range of about $1-5^{\circ} \mathrm{C}$. The aerosol forcing in theory can also be estimated from changes in the water cycle, but observations are insufficient and model errors too large to successfully do it at this point ${ }^{226}$.

Most of the above results depend on the sources of uncertainties considered (e.g., whether all forcing components or just the aerosol is assumed to be uncertain, on the structure of the model ${ }^{227}$, the length and type of data and its uncertainties that are used ${ }^{12,16}$, and on assumptions for priors and likelihoods ${ }^{18-20,185,193}$, more so for the earlier studies where the anthropogenic signal was weaker and observational uncertainties were larger than for the newer ones. Many are affected by the limitations of assuming constant feedbacks for all climate states and forcings in energy balance models, as discussed in the main text. This limitation, along with incomplete coverage and the blending of sea surface with land air temperature data ${ }^{4,22,228}$, likely biases results of many such studies low.

These energy balance and attribution results are consistent with estimates explicitly using the energy budget and radiative forcing estimates ${ }^{229}$, using understanding of feedbacks and processes as evident from observations and models ${ }^{3,230}$, and with observed and simulated changes in the global energy budget $^{150,231-241}$. Observed trends in clouds are also detectable and some are consistent with models ${ }^{242}$.

Estimates of TCR are generally better constrained by the recent warming, but TCR depends on the state of the ocean when initialized ${ }^{43,243-245}$ and - as ECS - measures the response to $\mathrm{CO}_{2}$ forcing only. 
Another important open question is the relation of inconstant feedbacks and TCR: the more feedbacks change through time the less representative TCR will be of the overall model behavior.

Results from both energy balance methods and detection and attribution can directly be used to generate future warming estimates for scenarios that are constrained by past warming $108,112,181,182,185,192,209,219-222,246-250$. Some results indicate that the observed warming is now powerful enough to reduce the range of predictions provided by models, e.g., by ruling out models with the strongest response as less likely ${ }^{108,221}$, but more recent studies indicate that some of these might have underestimated observed changes by comparing with model surface air tempreature rather than sea surface temperature over oceans ${ }^{4}$. The dependence on the model and assumptions in the method ${ }^{251}$ also question the robustness of those results.

A number of other statistical methods have been used to infer ECS from various historical and paleo time series ${ }^{252-255}$. Inferring the long term response from short term variability, e.g., through a flux dissipation theorem, has been tried since the $1970 s^{256-264}$. However, short term climate variations have long been known to provide a poor and unreliable constraint on the long term response ${ }^{132,169}$. Short term variations in the energy budget can be informative to compare feedbacks in models and observation, and relate them to long-term feedbacks in the form of an emergent constraint ${ }^{24,225,265-}$ 268 , but feedbacks depend on the timescale and are different for variability $231,269,270$. The results in such studies also hinge on assumptions on the response timescales, and are affected by limitations of simple models fitted. Many estimates based on those methods have therefore been criticized; we generally have low confidence in relying on them in this assessment, but provide further references to studies and critical comments here for completeness $s^{7,24,56,93,225,231,259,269,271-301}$. Similarly, the response to volcanic eruptions provides a test for models ${ }^{302}$ but in our view the implications for ECS are unclear since the timescale and type of forcing is very different, the feedbacks arising are different, and the response is difficult to separate from El Niño variability ${ }^{185,303-311}$. It has also been attempted to estimate TCR from the observed temperature response to the sunspot cycle ${ }^{312}$. The resulting estimate is higher than those based on other approaches and may be affected by different feedbacks for solar forcing and possibly aliasing of other forcings.

\section{Constraints from climatology}

The raw distribution or range of ECS and TCR simulated by models has been used in some studies ${ }^{313-}$ 315 , but the interpretation of that range is unclear as the model space is not sampled systematically and the degree of tuning of models is unknown ${ }^{316,317}$. But comprehensive models are routinely evaluated against climatological fields, including interannual variability and trends, and specific feedbacks are quantified ${ }^{318-320}$. Such evaluations of major feedbacks in a process based climate model can also be used to determine ECS by correlating observable quantities to ECS or TCR. In most cases correlations of general climatological mean patterns and variability to ECS or TCR are weak or model-dependent ${ }^{23,321-326}$. Despite the fact that newer models agree better with

observations ${ }^{7,96,327,328}$, their spread in the climate response has not decreased ${ }^{96,112}$, possibly because most observations have already been used to evaluate models ${ }^{329}$. Yet there have been studies that have constrained individual relevant feedbacks like the sea ice, snow albedo or cloud feedbacks ${ }^{180,265,330}$ and its implication on projections ${ }^{331,332}$.

Robust evidence based on many studies using PPE and CMIP show that a credible representation of the mean climate and variability is difficult to achieve with ECS below $2^{\circ} \mathrm{C}$, good agreement with observations favors values in the $2-4.5^{\circ} \mathrm{C}$ range, and most likely ECS values are close to or above the CMIP mean of about $3.2^{\circ} \mathrm{C}$ once emergent constraints are included $d^{99,110,180,324,333-356}$, consistent with studies constraining individual feedbacks suggesting that the net feedbacks are not small ${ }^{26-28,357-360}$. Questions remain about shared model biases and tuning techniques ${ }^{361-363}$, the robustness of 
emergent constraints in ensembles of opportunity ${ }^{364,365}$ and whether those ensembles sample the full range of ECS and TCR consistent with observations, in particular on the low end ${ }^{109,227}$. While high ECS values (in rare cases above $10^{\circ} \mathrm{C}$ ) were found in some PPE simulations, these are found to be much less likely based on model's climatology than values in the range of $2-4.5^{\circ} \mathrm{C}^{326,333-335,366-368}$. The largest source of model spread continues to be related to low level clouds and convection ${ }^{27,32,33,318,319,369-379}$.

Results based on emergent constraints depend on the metrics used ${ }^{110,324,380-390}$. A further issue is that the number of truly independent climate models in the overall ensemble is limited, and results may be biased towards near duplicate models ${ }^{23,110,328,383,388,391-396}$. As a result of the underlying small sample size, screening for predictors may lead to apparent relationships that are unphysical or unreliable ${ }^{324,337,365,397,398}$. As a result, weighted ensembles may be overconfident if the number of models is small or variability is large ${ }^{399}$.

\section{Paleoclimate}

Paleoclimate is a useful testbed for simple and complex climate models ${ }^{400-405}$ and numerous studies have estimated climate sensitivity from past periods, in particular the Last Glacial Maximum or the last few glacial cycles, but also the Holocene and warm periods millions of years back ${ }^{95,102,400,406-426}$. Uncertainties in some individual studies are small but the range across studies is similar to the range derived from other methods. Many studies find that climate sensitivity in the present and future differs from that inferred from past colder (glacial) or warmer states ${ }^{407,414,427-432}$, while others find little state dependence ${ }^{433,434}$. Including vegetation and ice sheet feedbacks can cause negative feedbacks ${ }^{435,436}$, but the overall Earth system sensitivity resulting from all feedbacks is consistently estimated to be higher than ECS ${ }^{8,420,437-445}$. This implies that ECS based on atmosphere-ocean climate models will underestimate warming on millennial timescales. If Earth system feedbacks are treated as additional forcings, as they generally are for example in ECS estimates from the Last Glacial Maximum, then the overall assessed paleoclimate constraints ${ }^{7,8,446}$ also support the consensus range of ECS, including its upper bound, but do not constrain it further.

\section{Expert elicitations}

A number of studies have summarized expert elicitations on ECS and TCR ${ }^{447-449}$. These largely agree with the conclusions here, but are obviously assessing the same studies. There is a desire for more formalized elicitations but this has not been done for ECS and TCR ${ }^{450}$. Sometimes such elicitations are used as prior information when estimating ECS ${ }^{183}$. However, the information used by the experts is not independent from that used to provide a posterior distribution.

\section{The transient climate response to cumulative carbon emissions}

There is strong and robust evidence from a variety of models that the transient warming, largely due to the long residence time of $\mathrm{CO}_{2}$ in the atmosphere, is approximately proportional to the total $\mathrm{CO}_{2}$ emitted $^{115,120,192,223,451-463}$, even though towards stabilization that proportionality does not hold in all models when emissions cease ${ }^{464-469}$. The proportionality arises from an approximate cancellation of multiple nonlinear effects, including the decrease in additional radiative forcing per unit $\mathrm{CO}_{2}$ at higher concentrations, the change in carbon sinks and therefore increase in the airborne fraction with emission rates and warming, and the unrealized warming in the system (TCR being lower than ECS).

\section{Illustrative combined constraint}

In Figure $5 \mathrm{a}$, the PDF for ECS estimated from the historical period is based on $\mathrm{Q}=\mathrm{F}-\lambda \mathrm{T}$ (see main text) using Gaussian distributions for $\mathrm{Q}=0.8 \pm 0.3 \mathrm{~W} / \mathrm{m}^{2}, \mathrm{~F}=2.0 \pm 0.6 \mathrm{~W} / \mathrm{m}^{2}, \mathrm{~T}=0.8 \pm 0.1^{\circ} \mathrm{C}$. The values are 
chosen to be approximately consistent with recent published estimates and to produce a PDF that reflects the range in recent studies ${ }^{11}$. The radiative forcing for $2 \mathrm{xCO}_{2}$ is assumed to be the standard value of $3.7 \mathrm{~W} / \mathrm{m}^{2}$ used in most studies. For the PDF of CMIP we assume a Gaussian distribution with $3.3 \pm 0.7^{\circ} \mathrm{C}$ for ECS centered on the CMIP5 mean, for paleoclimate a Gaussian distribution with 3. $0 \pm 0.7^{\circ} \mathrm{C}$. Values indicate \pm 1 standard deviation. The combined constraint as the product of the three PDFs ${ }^{94}$ is shown in black along with 'likely' (66\%) and 'very likely' $(90 \%)$ ranges. For a revised combined constraint (Figure $5 \mathrm{~b}$ ) we scale up the observed warming by $20 \pm 15 \%$ (ref. ${ }^{4}$ ), use a forcing of $3.4 \mathrm{~W} / \mathrm{m}^{2}$ for $2 \mathrm{xCO}_{2}$ that may be more appropriate for such regressions (see above), and scale up the sensitivity inferred from the $20^{\text {th }}$ century by $30 \pm 30 \%$ to account for changes in feedbacks (see above, and ref. ${ }^{59}$ ). The width of the CMIP and paleoclimate PDFs is doubled to account for biases and uncertainties not otherwise accounted for (e.g., feedbacks changing from cold to warm states, structural model biases), and for dependencies between estimates. We emphasize that such a toy model is insufficient for an assessment, and that other, defensible decisions would lead to slightly different overall ranges. However, it illustrates the value, and the challenges, of combining all the lines of evidence.

\section{Notes on figures}

Figures 1, 2 and 3 show published ranges of ECS and TCR over a wide range of studies with different assumptions and definitions of climate sensitivity. Some studies provide PDFs, others just ranges, with our without proper statistical descriptions of what those are. Some studies provide multiple ranges, in which case subjective judgement was used to select the most relevant or representative one. More details are given in the supplementary online table. Some studies show quite different ranges compared to other lines of evidence. However, many of these have not held up to tests estimating a model's known sensitivity, robustness tests or evaluation of their assumptions. These studies, those estimating somewhat different quantities, those arguing that there is no reliable constraint, and all those before 2008 (approximately predating the IPCC Fourth Assessment Report in 2007 and our earlier review) are marked in grey to indicate that those might not be the most reliable estimates, although we recognize that this is a judgement call and others might come to slightly different decisions on grey versus colored lines. The overall aim of the figures is to show the wide range of research on this topic, realizing that a like with like comparison of different estimates is difficult. The categorization, discussion and assessment of the many studies is solely the view of the authors of this review, but the overall conclusions do not depend on these choices.

Figure 4 includes simulations of $4 \times \mathrm{CO}_{2}$ forcing scenarios with the following CMIP5 models as grey lines (each 150 years long): ACCESS1-0, ACCESS1-3, bcc-csm1-1-m, bcc-csm1-1, CanESM2, CCSM4, CNRM-CM5, CSIRO-Mk3-6-0, FGOALS-g2, GFDL-CM3, GFDL-ESM2M, GFDL-ESM2G, inmcm4, IPSLCM5A-LR, IPSL-CM5B-LR, MIROC5, MIROC-ESM, MPI-ESM-LR, MPI-ESM-MR, MPI-ESM-P, MRICGCM3, NorESM1-M. For CESM 3675 years of a simulation with a step change to $4 \times \mathrm{XO}_{2}$ are shown, based on data from ref. ${ }^{3}$. The implied ECS numbers are the extrapolation of the blue, red and orange lines to zero imbalance, divided by two to obtain the values for $\mathrm{CO}_{2}$ doubling instead of quadrupling. 


\section{References}

1. Arrhenius, S. On the influence of carbonic acid in the air upon the temperature of the ground. Philos. Mag. Ser. 5 41, 237-276 (1896).

2. Callendar, G. S. The artificial production of carbon dioxide and its influence on temperature. Quarterly Journal Royal Meteorological Society 64, 223-240 (1938).

3. Knutti, R. \& Rugenstein, M. A. A. Feedbacks, climate sensitivity and the limits of linear models. Philos. Trans. R. Soc. A Math. Phys. Eng. Sci. 373, 20150146 (2015).

4. Richardson, M., Cowtan, K., Hawkins, E. \& Stolpe, M. B. Reconciled climate response estimates from climate models and the energy budget of Earth. Nat. Clim. Chang. 1-6 (2016). doi:10.1038/nclimate3066

5. Hope, C. The $\$ 10$ trillion value of better information about the transient climate response. Philos. Trans. R. Soc. A Math. Phys. Eng. Sci. 373, 20140429 (2015).

6. Knutti, R. \& Hegerl, G. C. The equilibrium sensitivity of the Earth's temperature to radiation changes. Nat. Geosci. 1, 735-743 (2008).

7. IPCC. Climate Change 2013: The physical science basis. Contribution of working group I to the Fifth Assessment Report of the Intergovernmental Panel on Climate Change. (Cambridge University Press, 2013).

8. PALEOSENS Project Members. Making sense of palaeoclimate sensitivity. Nature 491, 683691 (2012).

9. Charney, J. et al. Carbon dioxide and climate : A scientific assessment. Natl. Acad. Sci. Press Washingt. DC 33 (1979).

10. Hegerl, G. \& Zwiers, F. Use of models in detection and attribution of climate change. Wiley Interdiscip. Rev. Clim. Chang. 2, 570-591 (2011).

11. Otto, A. et al. Energy budget constraints on climate response. Nat. Geosci. 6, 415-416 (2013).

12. Huber, M., Beyerle, U. \& Knutti, R. Estimating climate sensitivity and future temperature in the presence of natural climate variability. Geophys. Res. Lett. 41, 2086-2092 (2014).

13. Olson, R. et al. What is the effect of unresolved internal climate variability on climate sensitivity estimates? J. Geophys. Res. Atmos. 118, 4348-4358 (2013).

14. Stevens, B. Rethinking the lower bound on aerosol radiative forcing. J. Clim. 28, 4794-4819 (2015).

15. Medhaug, I., Stolpe, M. B., Fischer, E. M. \& Knutti, R. Reconciling controversies about the 'global warming hiatus'. Nature 545, 41-47 (2017).

16. Johansson, D. J. A., O’Neill, B. C., Tebaldi, C. \& Häggström, O. Equilibrium climate sensitivity in light of observations over the warming hiatus. Nat. Clim. Chang. 5, 449-453 (2015).

17. Lewis, N. \& Curry, J. A. The implications for climate sensitivity of AR5 forcing and heat uptake estimates. Clim. Dyn. 45, 1009-1023 (2015).

18. Lewis, N. Objective inference for climate parameters: Bayesian, transformation-of-variables, and profile likelihood approaches. J. Clim. 27, 7270-7284 (2014).

19. Annan, J. D. \& Hargreaves, J. C. On the generation and interpretation of probabilistic estimates of climate sensitivity. Clim. Change 104, 423-436 (2011). 
20. Annan, J. D. Recent developments in Bayesian estimation of climate sensitivity. Curr. Clim. Chang. Reports 1, 263-267 (2015).

21. Skeie, R. B., Berntsen, T., Aldrin, M., Holden, M. \& Myhre, G. A lower and more constrained estimate of climate sensitivity using updated observations and detailed radiative forcing time series. Earth Syst. Dyn. 5, 139-175 (2014).

22. Karl, T. R. et al. Possible artifacts of data biases in the recent global surface warming hiatus. Science 348, 1469-1472 (2015).

23. Tebaldi, C. \& Knutti, R. The use of the multi-model ensemble in probabilistic climate projections. Philos. Trans. R. Soc. A Math. Phys. Eng. Sci. 365, 2053-2075 (2007).

24. Dessler, A. E. A determination of the cloud feedback from climate variations over the past decade. Science 330, 1523-1527 (2010).

25. Mauritsen, T. \& Stevens, B. Missing Iris effect as a possible cause of muted hydrological change and high climate sensitivity in models. Nat. Geosci. 8, 346-351 (2015).

26. Zelinka, M. D., Zhou, C. \& Klein, S. A. Insights from a refined decomposition of cloud feedbacks. Geophys. Res. Lett. 43, 1-11 (2016).

27. Caldwell, P. M., Zelinka, M. D., Taylor, K. E. \& Marvel, K. Quantifying the sources of intermodel spread in equilibrium climate sensitivity. J. Clim. 29, 513-524 (2016).

28. Stevens, B. \& Bony, S. Water in the atmosphere. Phys. Today 66, 29 (2013).

29. Donohoe, A., Armour, K. C., Pendergrass, A. G. \& Battisti, D. S. Shortwave and longwave radiative contributions to global warming under increasing CO2. Proc. Natl. Acad. Sci. 111, 16700-16705 (2014).

30. Harris, G. R., Sexton, D. M. H., Booth, B. B. B., Collins, M. \& Murphy, J. M. Probabilistic projections of transient climate change. Clim. Dyn. 40, 2937-2972 (2013).

31. Hawkins, E., Dong, B., Robson, J., Sutton, R. \& Smith, D. The interpretation and use of biases in decadal climate predictions. J. Clim. 27, 2931-2947 (2014).

32. Stevens, B., Sherwood, S. C., Bony, S. \& Webb, M. J. Prospects for narrowing bounds on Earth's equilibrium climate sensitivity. Earth's Futur. 4, 512-522 (2016).

33. Cess, R. D. et al. Interpretation of cloud-climate feedback as produced by 14 atmospheric general circulation models. Science 245, 513-516 (1989).

34. Samset, B. H., Myhre, G. \& Schulz, M. Upward adjustment needed for aerosol radiative forcing uncertainty. Nat. Clim. Chang. 4, 230-232 (2014).

35. Carslaw, K. S. et al. Large contribution of natural aerosols to uncertainty in indirect forcing. Nature 503, 67-71 (2013).

36. Gregory, J. M. A new method for diagnosing radiative forcing and climate sensitivity. Geophys. Res. Lett. 31, L03205 (2004).

37. Boer, G. J., Hamilton, K. \& Zhu, W. Climate sensitivity and climate change under strong forcing. Clim. Dyn. 24, 685-700 (2005).

38. Armour, K. C., Bitz, C. M. \& Roe, G. H. Time-varying climate sensitivity from regional feedbacks. J. Clim. 26, 4518-4534 (2013).

39. Rose, B. E. J., Armour, K. C., Battisti, D. S., Feldl, N. \& Koll, D. D. B. The dependence of transient climate sensitivity and radiative feedbacks on the spatial pattern of ocean heat 
uptake. Geophys. Res. Lett. 41, 1071-1078 (2014).

40. Feldl, N. \& Roe, G. H. The nonlinear and nonlocal nature of climate feedbacks. J. Clim. 26, 8289-8304 (2013).

41. Rugenstein, M. A. A., Caldeira, K. \& Knutti, R. Dependence of global radiative feedbacks on evolving patterns of surface heat fluxes. Geophys. Res. Lett. 43, 9877-9885 (2016).

42. Rose, B. E. J. \& Rayborn, L. The effects of ocean heat uptake on transient climate sensitivity. Curr. Clim. Chang. Reports (2016). doi:10.1007/s40641-016-0048-4

43. Winton, M. et al. Has coarse ocean resolution biased simulations of transient climate sensitivity? Geophys. Res. Lett. 41, 8522-8529 (2014).

44. Knutti, R. \& Tomassini, L. Constraints on the transient climate response from observed global temperature and ocean heat uptake. Geophys. Res. Lett. 35, L09701 (2008).

45. Murphy, J. M. Transient response of the Hadley Centre coupled ocean-atmosphere model to increasing carbon dioxide. Part III: Analysis of global-mean response using simple models. J. Clim. 8, 496-514 (1995).

46. Senior, C. A. \& Mitchell, J. F. B. The time-dependence of climate sensitivity. Geophys. Res. Lett. 27, 2685-2688 (2000).

47. Andrews, T., Gregory, J. M. \& Webb, M. J. The dependence of radiative forcing and feedback on evolving patterns of surface temperature change in climate models. J. Clim. 28, 1630-1648 (2015).

48. Gregory, J. M., Andrews, T. \& Good, P. The inconstancy of the transient climate response parameter under increasing $\mathrm{CO}_{2}$. Philos. Trans. R. Soc. A Math. Phys. Eng. Sci. 373, 20140417 (2015).

49. Winton, M., Takahashi, K. \& Held, I. M. Importance of ocean heat uptake efficacy to transient climate change. J. Clim. 23, 2333-2344 (2010).

50. Geoffroy, O. et al. Transient climate response in a two-layer energy-balance model. Part I: Analytical solution and parameter calibration using CMIP5 AOGCM experiments. J. Clim. 26, 1841-1857 (2013).

51. Geoffroy, O. et al. Transient climate response in a two-layer energy-balance model. Part II: Representation of the efficacy of deep-ocean heat uptake and validation for CMIP5 AOGCMs. J. Clim. 26, 1859-1876 (2013).

52. Yoshimori, M. et al. A review of progress towards understanding the transient global mean surface temperature response to radiative perturbation. Prog. Earth Planet. Sci. 3, 21 (2016).

53. Bloch-Johnson, J., Pierrehumbert, R. T. \& Abbot, D. S. Feedback temperature dependence determines the risk of high warming. Geophys. Res. Lett. 42, 4973-4980 (2015).

54. Gregory, J. M. \& Andrews, T. Variation in climate sensitivity and feedback parameters during the historical period. Geophys. Res. Lett. 43, 3911-3920 (2016).

55. Boer, G. J. \& Yu, B. Climate sensitivity and climate state. Clim. Dyn. 21, 167-176 (2003).

56. Loeb, N. G., Su, W. \& Kato, S. Understanding climate feedbacks and sensitivity using observations of Earth's energy budget. Curr. Clim. Chang. Reports 2, 170-178 (2016).

57. Long, D. J. \& Collins, M. Quantifying global climate feedbacks, responses and forcing under abrupt and gradual $\mathrm{CO}_{2}$ forcing. Clim. Dyn. 41, 2471-2479 (2013). 
58. Williams, K. D., Ingram, W. J. \& Gregory, J. M. Time variation of effective climate sensitivity in GCMs. J. Clim. 21, 5076-5090 (2008).

59. Armour, K. C. Energy budget constraints on climate sensitivity in light of inconstant climate feedbacks. Nat. Clim. Chang. 7, 331-335 (2017).

60. Proistosescu, C. \& Huybers, P. J. Slow climate mode reconciles historical and model-based estimates of climate sensitivity. Sci. Adv. 3, e1602821 (2017).

61. Meraner, K., Mauritsen, T. \& Voigt, A. Robust increase in equilibrium climate sensitivity under global warming. Geophys. Res. Lett. 40, 5944-5948 (2013).

62. Zhou, C., Zelinka, M. D. \& Klein, S. A. Impact of decadal cloud variations on the Earth's energy budget. Nat. Geosci. 9, 871-874 (2016).

63. Mauritsen, T. et al. Climate feedback efficiency and synergy. Clim. Dyn. 41, 2539-2554 (2013)

64. Schaller, N., Sedlacek, J. \& Knutti, R. The asymmetry of the climate system's response to solar forcing changes and its implications for geoengineering scenarios. J. Geophys. Res. Atmos. 119, 5171-5184 (2014).

65. Shindell, D. T. Inhomogeneous forcing and transient climate sensitivity. Nat. Clim. Chang. 4, 274-277 (2014).

66. Davin, E. L., de Noblet-Ducoudré, N. \& Friedlingstein, P. Impact of land cover change on surface climate: Relevance of the radiative forcing concept. Geophys. Res. Lett. 34, L13702 (2007).

67. Marvel, K. et al. Do responses to different anthropogenic forcings add linearly in climate models? Environ. Res. Lett. 10, 104010 (2015).

68. Marvel, K., Schmidt, G. A., Miller, R. L. \& Nazarenko, L. S. Implications for climate sensitivity from the response to individual forcings. Nat. Clim. Chang. 6, 386-389 (2015).

69. Crook, J. A., Forster, P. M. \& Stuber, N. Spatial patterns of modeled climate feedback and contributions to temperature response and polar amplification. J. Clim. 24, 3575-3592 (2011).

70. Colman, R. \& McAvaney, B. Climate feedbacks under a very broad range of forcing. Geophys. Res. Lett. 36, L01702 (2009).

71. Huneeus, N. et al. Forcings and feedbacks in the GeoMIP ensemble for a reduction in solar irradiance and increase in $\mathrm{CO}_{2}$. J. Geophys. Res. Atmos. 119, 5226-5239 (2014).

72. Kummer, J. R. \& Dessler, A. E. The impact of forcing efficacy on the equilibrium climate sensitivity. Geophys. Res. Lett. 41, 3565-3568 (2014).

73. Stott, P. A., Jones, G. S. \& Mitchell, J. F. B. Do models underestimate the solar contribution to recent climate change? J. Clim. 16, 4079-4093 (2003).

74. Wang, W.-C., Dudek, M. P., Liang, X.-Z. \& Kiehl, J. T. Inadequacy of effective $\mathrm{CO}_{2}$ as a proxy in simulating the greenhouse effect of other radiatively active gases. Nature $350,573-577$ (1991).

75. Good, P. et al. Nonlinear regional warming with increasing $\mathrm{CO}_{2}$ concentrations. Nat. Clim. Chang. 5, 138-142 (2015).

76. Gregory, J. M., Andrews, T., Good, P., Mauritsen, T. \& Forster, P. M. Small global-mean cooling due to volcanic radiative forcing. Clim. Dyn. 47, 3979-3991 (2016).

77. Andrews, T., Ringer, M. A., Doutriaux-Boucher, M., Webb, M. J. \& Collins, W. J. Sensitivity of 
an Earth system climate model to idealized radiative forcing. Geophys. Res. Lett. 39, L10702 (2012).

78. Hansen, J. E., Sato, M. \& Ruedy, R. Radiative forcing and climate response. J. Geophys. Res. 102, 6831-6864 (1997).

79. Modak, A., Bala, G., Cao, L. \& Caldeira, K. Why must a solar forcing be larger than a $\mathrm{CO}_{2}$ forcing to cause the same global mean surface temperature change? Environ. Res. Lett. 11, 44013 (2016).

80. Rieger, V. S., Dietmüller, S. \& Ponater, M. Can feedback analysis be used to uncover the physical origin of climate sensitivity and efficacy differences? Clim. Dyn. (2016). doi:10.1007/s00382-016-3476-x

81. Gettelman, A., Lin, L., Medeiros, B. \& Olson, J. Climate feedback variance and the interaction of aerosol forcing and feedbacks. J. Clim. 29, 6659-6675 (2016).

82. Andrews, T. \& Forster, P. M. $\mathrm{CO}_{2}$ forcing induces semi-direct effects with consequences for climate feedback interpretations. Geophys. Res. Lett. 35, L04802 (2008).

83. Gregory, J. \& Webb, M. Tropospheric adjustment induces a cloud component in $\mathrm{CO}_{2}$ forcing. J. Clim. 21, 58-71 (2008).

84. Rugenstein, M. A. A., Gregory, J. M., Schaller, N., Sedláček, J. \& Knutti, R. Multiannual OceanAtmosphere Adjustments to Radiative Forcing. J. Clim. 29, 5643-5659 (2016).

85. Colman, R. A. \& McAvaney, B. J. On tropospheric adjustment to forcing and climate feedbacks. Clim. Dyn. 36, 1649-1658 (2011).

86. Sherwood, S. C. et al. Adjustments in the forcing-feedback framework for understanding climate change. Bull. Am. Meteorol. Soc. 96, 217-228 (2015).

87. Hansen, J. et al. Efficacy of climate forcings. J. Geophys. Res. D Atmos. 110, 1-45 (2005).

88. Stuber, N., Ponater, M. \& Sausen, R. Why radiative forcing might fail as a predictor of climate change. Clim. Dyn. 24, 497-510 (2005).

89. Andrews, T., Gregory, J. M., Forster, P. M. \& Webb, M. J. Cloud adjustment and its role in $\mathrm{CO}_{2}$ radiative forcing and climate sensitivity: A review. Surv. Geophys. 33, 619-635 (2011).

90. Kamae, Y., Watanabe, M., Ogura, T., Yoshimori, M. \& Shiogama, H. Rapid adjustments of cloud and hydrological cycle to increasing CO2: A review. Curr. Clim. Chang. Reports 1, 103-113 (2015).

91. Forster, P. M. et al. Recommendations for diagnosing effective radiative forcing from climate models for CMIP6. J. Geophys. Res. Atmos. 121, 12,460-12,475 (2016).

92. Paynter, D. \& Frölicher, T. L. Sensitivity of radiative forcing, ocean heat uptake, and climate feedback to changes in anthropogenic greenhouse gases and aerosols. J. Geophys. Res. Atmos. 120, 9837-9854 (2015).

93. Knutti, R., Krähenmann, S., Frame, D. J. \& Allen, M. R. Comment on 'Heat capacity, time constant, and sensitivity of Earth's climate system' by S. E. Schwartz. J. Geophys. Res. 113, D15103 (2008).

94. Annan, J. D. \& Hargreaves, J. C. Using multiple observationally-based constraints to estimate climate sensitivity. Geophys. Res. Lett. 33, L06704 (2006).

95. Hegerl, G. C., Crowley, T. J., Hyde, W. T. \& Frame, D. J. Climate sensitivity constrained by temperature reconstructions over the past seven centuries. Nature 440, 1029-1032 (2006). 
96. Knutti, R. \& Sedláček, J. Robustness and uncertainties in the new CMIP5 climate model projections. Nat. Clim. Chang. 3, 369-373 (2012).

97. Urban, N. M., Holden, P. B., Edwards, N. R., Sriver, R. L. \& Keller, K. Historical and future learning about climate sensitivity. Geophys. Res. Lett. 41, 2543-2552 (2014).

98. Myhre, G., Boucher, O., Bréon, F.-M., Forster, P. \& Shindell, D. Declining uncertainty in transient climate response as $\mathrm{CO}_{2}$ forcing dominates future climate change. Nat. Geosci. 8, 181-185 (2015).

99. Fasullo, J. T., Sanderson, B. M. \& Trenberth, K. E. Recent progress in constraining climate sensitivity with model ensembles. Curr. Clim. Chang. Reports 1, 268-275 (2015).

100. Li, F., Rosa, D., Collins, W. D. \& Wehner, M. F. 'Super-parameterization': A better way to simulate regional extreme precipitation? J. Adv. Model. Earth Syst. 4, M04002 (2012).

101. Schneider, T. et al. Climate goals and computing the future of clouds. Nat. Clim. Chang. 7, 3-5 (2017).

102. Hargreaves, J. C. \& Annan, J. D. Could the Pliocene constrain the equilibrium climate sensitivity? Clim. Past 12, 1591-1599 (2016).

103. Weitzman, M. L. Fat-tailed uncertainty in the economics of catastrophic climate change. Rev. Environ. Econ. Policy 5, 275-292 (2011).

104. Allen, M. R. \& Frame, D. J. Call off the quest. Science 318, 582-583 (2007).

105. van der Sluijs, J., van Eijndhoven, J., Shackley, S. \& Wynne, B. Anchoring devices in science for policy: The case of consensus around climate sensitivity. Soc. Stud. Sci. 28, 291-323 (1998).

106. Otto, A., Todd, B. J., Bowerman, N., Frame, D. J. \& Allen, M. R. Climate system properties determining the social cost of carbon. Environ. Res. Lett. 8, 24032 (2013).

107. Shiogama, H. et al. Predicting future uncertainty constraints on global warming projections. Sci. Rep. 6, 18903 (2016).

108. Stott, P., Good, P., Jones, G., Gillett, N. \& Hawkins, E. The upper end of climate model temperature projections is inconsistent with past warming. Environ. Res. Lett. 8, 14024 (2013).

109. Gillett, N. P. Weighting climate model projections using observational constraints. Philos. Trans. R. Soc. A Math. Phys. Eng. Sci. 373, 20140425 (2015).

110. Sanderson, B. M., Knutti, R. \& Caldwell, P. Addressing interdependency in a multimodel ensemble by interpolation of model properties. J. Clim. 28, 5150-5170 (2015).

111. Rowlands, D. J. et al. Broad range of 2050 warming from an observationally constrained large climate model ensemble. Nat. Geosci. 5, 256-260 (2012).

112. Knutti, R. et al. A review of uncertainties in global temperature projections over the twentyfirst century. J. Clim. 21, 2651-2663 (2008).

113. Rogelj, J., Meinshausen, M., Sedláček, J. \& Knutti, R. Implications of potentially lower climate sensitivity on climate projections and policy. Environ. Res. Lett. 9, 31003 (2014).

114. Knutti, R., Rogelj, J., Sedláček, J. \& Fischer, E. M. A scientific critique of the two-degree climate change target. Nat. Geosci. 9, 13-18 (2015).

115. Rogelj, J. et al. Differences between carbon budget estimates unravelled. Nat. Clim. Chang. 6, 245-252 (2016). 
116. Hawkins, E. et al. Estimating changes in global temperature since the pre-industrial period. Bull. Am. Meteorol. Soc. (2017). doi:10.1175/BAMS-D-16-0007.1

117. Schurer, A. P., Mann, M. E., Hawkins, E., Tett, S. F. B. \& Hegerl, G. C. Importance of preindustrial baseline for determining the likelihood of exceeding the Paris limits. Nat. Clim. Chang. (2017). doi:10.1038/NCLIMATE3345

118. Rogelj, J. et al. Disentangling the effects of $\mathrm{CO}_{2}$ and short-lived climate forcer mitigation. Proc. Natl. Acad. Sci. 111, 2-7 (2014).

119. Robiou du Pont, Y. et al. Equitable mitigation to achieve the Paris Agreement goals. Nat. Clim. Chang. 7, 38-43 (2016).

120. Knutti, R. \& Rogelj, J. The legacy of our $\mathrm{CO}_{2}$ emissions: a clash of scientific facts, politics and ethics. Clim. Change 133, 361-373 (2015).

121. Raupach, M. R. et al. Sharing a quota on cumulative carbon emissions. Nat. Clim. Chang. (2014). doi:10.1038/nclimate2384

122. Sanderson, B. M. \& Knutti, R. Delays in US mitigation could rule out Paris targets. Nat. Clim. Chang. (2016).

123. Rogelj, J. et al. Paris Agreement climate proposals need a boost to keep warming well below $2^{\circ} \mathrm{C}$. Nature 534, 631-639 (2016).

124. Hulburt, E. O. The temperature of the lower atmosphere of the Earth. Phys. Rev. 38, 18761890 (1931).

125. Plass, G. N. The carbon dioxide theory of climatic change. Tellus 8, 140-154 (1956).

126. Möller, F. On the influence of changes in the $\mathrm{CO}_{2}$ concentration in air on the radiation balance of the Earth's surface and on the climate. J. Geophys. Res. 68, 3877-3886 (1963).

127. North, G. R., Cahalan, R. F. \& Coakley Jr, J. A. Energy balance climate models. Rev. Geophys. 19, 91-121 (1981).

128. Hansen, J. et al. Climate response times: Dependence on climate sensitivity and ocean mixing. Science 229, 857 (1985).

129. Budyko, M. I. The effect of solar radiation variations on the climate of the Earth. Tellus 21, 611-619 (1969).

130. Wigley, T. M. L. \& Schlesinger, M. Analytical solution for the effect of increasing $\mathrm{CO}_{2}$ on global mean temperature. Nature 315, 649-652 (1985).

131. Sellers, W. D. A global climate model based on the energy balance of the earth-atmosphere system. J. Appl. Meteorol. 8, 392-400 (1969).

132. Wigley, T. M. L. \& Raper, S. Natural variability of the climate system and detection of the greenhouse effect. Nature 344, 324-326 (1990).

133. Manabe, S. \& Wetherald, R. T. The effects of doubling the $\mathrm{CO}_{2}$ concentration on the climate of a general circulation model. J. Atmos. Sci. 32, 3-15 (1975).

134. Manabe, S. \& Stouffer, R. J. Sensitivity of a global climate model to an increase of $\mathrm{CO}_{2}$ concentration in the atmosphere. J. Geophys. Res. 85, 5529-54 (1980).

135. Wetherald, R. T. \& Manabe, S. Cloud cover and climate sensitivity. Journal of the Atmospheric Sciences 37, 1485-1510 (1980). 
136. Hansen, J. E. et al. Climate sensitivity: Analysis of feedback mechanisms. Clim. Process. Clim. Sensit. 5, 130-163 (1984).

137. Manabe, S. \& Wetherald, R. T. Thermal equilibrium of the atmosphere with a given distribution of relative humidity. Journal of the Atmospheric Sciences 24, 241-259 (1967).

138. Ramanathan, V. Increased atmosheric $\mathrm{CO}_{2}$ - Zonal and seasonal estimates of the effect on the radiation energy balance and surface temperature. Journal of Geophysical Research 84, 49494958 (1979).

139. Augustsson, T. \& Ramanathan, V. A radiative-convective model study of the $\mathrm{CO}_{2}$ climate problem. J. Atmos. Sci. 34, 448-451 (1977).

140. Lorius, C., Jouzel, J., Raynaud, D., Hansen, J. E. \& Le Treut, H. The ice-core record: climate sensitivity and future greenhouse warming. Nature 347, 139-145 (1990).

141. Hoffert, M. I. \& Covey, C. Deriving global climate sensitivity from paleoclimate studies. Nature 360, 573-575 (1992).

142. Covey, C., Sloan, L. C. \& Hoffert, M. I. Paleoclimate data constraints on climate sensitivity: The paleocalibration method. Clim. Change 32, 165-184 (1996).

143. Specht, E., Redemann, T. \& Lorenz, N. Simplified mathematical model for calculating global warming through anthropogenic $\mathrm{CO}_{2}$. Int. J. Therm. Sci. 102, 1-8 (2016).

144. Harde, $\mathrm{H}$. Advanced two-layer climate model for the assessment of global warming by $\mathrm{CO}_{2}$. Open J. Atmos. Clim. Chang. 2014, 1-51 (2014).

145. Idso, S. B. $\mathrm{CO}_{2}$-induced global warming : a skeptic's view of potential climate change. Clim. Res. 10, 69-82 (1998).

146. Roe, G. H. \& Armour, K. C. How sensitive is climate sensitivity? Geophys. Res. Lett. 38, L14708 (2011).

147. Harde, $\mathrm{H}$. Radiation transfer calculations and assessment of global warming by $\mathrm{CO}_{2}$. Int. J. Atmos. Sci. 2017, 1-30 (2017).

148. Stouffer, R. J. Time scales of climate response. J. Clim. 17, 209-217 (2004).

149. Held, I. M. et al. Probing the fast and slow components of global warming by returning abruptly to preindustrial forcing. J. Clim. 23, 2418-2427 (2010).

150. Hansen, J., Sato, M., Kharecha, P. \& von Schuckmann, K. Earth's energy imbalance and implications. Atmos. Chem. Phys. 11, 13421-13449 (2011).

151. Rugenstein, M. A. A., Sedláček, J. \& Knutti, R. Nonlinearities in patterns of long-term ocean warming. Geophys. Res. Lett. 43, 3380-3388 (2016).

152. Caldeira, K. \& Myhrvold, N. P. Projections of the pace of warming following an abrupt increase in atmospheric carbon dioxide concentration. Environ. Res. Lett. 8, 34039 (2013).

153. Dickinson, R. E. \& Schaudt, K. J. Analysis of timescales of response of a simple climate model. J. Clim. 11, 97-106 (1998).

154. Harvey, L. D. D. \& Schneider, S. H. Transient climate response to external forcing on $10^{\circ}-10^{4}$ year time scales, Part 1: experiments with globally averaged, coupled, atmosphere and ocean energy balance models. J. Geophys. Res. 90, 2191-2205 (1985).

155. Jarvis, A. The magnitude-timescale relationship of surface temperature feedbacks in climate models. Earth Syst. Dyn. Discuss. 2, 467-491 (2011). 
156. Li, S. \& Jarvis, A. Long run surface temperature dynamics of an A-OGCM: the $\mathrm{HadCM} 34 \times \mathrm{CO}_{2}$ forcing experiment revisited. Clim. Dyn. 33, 817-825 (2009).

157. Watts, R. G., Morantine, M. C. \& Achutarao, K. Timescales in energy balance climate models. 1. The limiting case solutions. J. Geophys. Res. 99, 3631-3641 (1994).

158. Morantine, M. C. \& Watts, R. G. Time scales in energy balance climate models. 2: The intermediate time solutions. J. Geophys. Res. 99, 3643-3653 (1994).

159. Olivié, D. J. L., Peters, G. P. \& Saint-Martin, D. Atmosphere response time scales estimated from AOGCM experiments. J. Clim. 25, 7956-7972 (2012).

160. Schneider, S. H. \& Thompson, S. L. Atmospheric $\mathrm{CO}_{2}$ and climate: Importance of the transient response. J. Geophys. Res. 86, 3135-3147 (1981).

161. Padilla, L. E., Vallis, G. K. \& Rowley, C. W. Probabilistic estimates of transient climate sensitivity subject to uncertainty in forcing and natural variability. J. Clim. 24, 5521-5537 (2011).

162. Knutti, R. Probabilistic climate change projections for $\mathrm{CO}_{2}$ stabilization profiles. Geophys. Res. Lett. 32, L20707 (2005).

163. Frame, D. J., Stone, D. A., Stott, P. A. \& Allen, M. R. Alternatives to stabilization scenarios. Geophys. Res. Lett. 33, L14707 (2006).

164. Gregory, J. M. \& Forster, P. M. Transient climate response estimated from radiative forcing and observed temperature change. J. Geophys. Res. 113, D23105 (2008).

165. Armour, K. C. \& Roe, G. H. Climate commitment in an uncertain world. Geophys. Res. Lett. 38, L01707 (2011).

166. Meehl, G. A., Washington, W. M. \& Collins, W. D. How much more global warming and sea level rise? Science 307, 1769-1773 (2005).

167. Hare, B. \& Meinshausen, M. How much warming are we committed to and how much can be avoided? Clim. Change 75, 111-149 (2006).

168. Harvey, L. D. D. Transient climatic response to an increase of greenhouse gases. Clim. Change 15, 15-30 (1989).

169. Allen, M. R. et al. in Avoiding Dangerous Climate Change 281-290 (2005).

170. Plattner, G. K. et al. Long-term climate commitments projected with climate-carbon cycle models. J. Clim. 21, 2721-2751 (2008).

171. Siegenthaler, U. \& Oeschger, H. Transient temperature changes due to increasing $\mathrm{CO}_{2}$ using simple models. Ann. Glaciol. 5, 153-159 (1984).

172. Bryan, K., Komro, F., Manabe, S. \& Spelman, M. Transient climate response to increasing atmospheric carbon dioxide. Science 215, 56 (1982).

173. Myhre, G., Highwood, E. J., Shine, K. P. \& Stordal, F. New estimates of radiative forcing due to well mixed greenhouse gases. Geophys. Res. Lett. 25, 2715-2718 (1998).

174. Chung, E.-S. \& Soden, B. J. An assessment of direct radiative forcing, radiative adjustments, and radiative feedbacks in coupled ocean-atmosphere models. J. Clim. 28, 4152-4170 (2015).

175. Roe, G. H. \& Baker, M. B. Comment on 'Another look at climate sensitivity' by Zaliapin and Ghil (2010). Nonlinear Process. Geophys. 18, 125-127 (2011). 
176. Zaliapin, I. \& Ghil, M. Another look at climate sensitivity. Nonlinear Process. Geophys. 17, 113122 (2010).

177. Roe, G. H. \& Baker, M. B. Why is climate sensitivity so unpredictable? Science $\mathbf{3 1 8 , 6 2 9 - 6 3 2}$ (2007).

178. Hannart, A., Dufresne, J.-L. \& Naveau, P. Why climate sensitivity may not be so unpredictable. Geophys. Res. Lett. 36, L16707 (2009).

179. Baker, M. B. \& Roe, G. H. The shape of things to come: Why is climate change so predictable? J. Clim. 22, 4574-4589 (2009).

180. Klein, S. A. \& Hall, A. Emergent constraints for cloud feedbacks. Curr. Clim. Chang. Reports 1, 276-287 (2015).

181. Knutti, R., Stocker, T. F., Joos, F. \& Plattner, G.-K. Constraints on radiative forcing and future climate change from observations and climate model ensembles. Nature 416, 719-723 (2002).

182. Knutti, R., Stocker, T. F., Joos, F. \& Plattner, G.-K. K. Probabilistic climate change projections using neural networks. Clim. Dyn. 21, 257-272 (2003).

183. Forest, C. E., Stone, P. H., Sokolov, A. P., Allen, M. R. \& Webster, M. D. Quantifying uncertainties in climate system properties with the use of recent climate observations. Science 295, 113-117 (2002).

184. Andronova, N. G. \& Schlesinger, M. E. Objective estimation of the probability density function for climate sensitivity. J. Geophys. Res. Atmos. 106, 22605-22611 (2001).

185. Frame, D. J. Constraining climate forecasts: The role of prior assumptions. Geophys. Res. Lett. 32, L09702 (2005).

186. Forster, P. M. D. F. \& Gregory, J. M. The climate sensitivity and its components diagnosed from Earth radiation budget data. J. Clim. 19, 39-52 (2006).

187. Forster, P. M. F. \& Taylor, K. E. Climate forcings and climate sensitivities diagnosed from coupled climate model integrations. J. Clim. 19, 6181-6194 (2006).

188. Gregory, J. M., Stouffer, R. J., Raper, S. C. B., Stott, P. A. \& Rayner, N. A. An observationally based estimate of the climate sensitivity. J. Clim. 15, 3117-3121 (2002).

189. Masters, T. Observational estimate of climate sensitivity from changes in the rate of ocean heat uptake and comparison to CMIP5 models. Clim. Dyn. 42, 2173-2181 (2014).

190. Aldrin, M. et al. Bayesian estimation of climate sensitivity based on a simple climate model fitted to observations of hemispheric temperatures and global ocean heat content. Environmetrics 23, 253-271 (2012).

191. Tomassini, L. et al. Robust Bayesian uncertainty analysis of climate system properties using Markov Chain Monte Carlo methods. J. Clim. 20, 1239 (2007).

192. Meinshausen, M. et al. Greenhouse-gas emission targets for limiting global warming to $2^{\circ} \mathrm{C}$. Nature 458, 1158-1162 (2009).

193. Lewis, N. An objective Bayesian improved approach for applying optimal fingerprint techniques to estimate climate sensitivity. J. Clim. 26, 7414-7429 (2013).

194. Olson, R. et al. A climate sensitivity estimate using Bayesian fusion of instrumental observations and an Earth System model. J. Geophys. Res. Atmos. 117, D04103 (2012). 
195. J. Ring, M. \& E. Schlesinger, M. Bayesian learning of climate sensitivity I: Synthetic observations. Atmos. Clim. Sci. 2, 464-473 (2012).

196. Sanso, B., Forest, C. E. \& Zantedeschi, D. Inferring climate system properties using a computer model. Bayesian Anal. 3, 1-37 (2008).

197. Forest, C. E., Stone, P. H. \& Sokolov, A. P. Constraining climate model parameters from observed 20th century changes. Tellus, Ser. A Dyn. Meteorol. Oceanogr. 60, 911-920 (2008).

198. Forest, C. E., Stone, P. H. \& Sokolov, A. P. Estimated PDFs of climate system properties including natural and anthropogenic forcings. Geophys. Res. Lett. 33, L01705 (2006).

199. Sansó, B. \& Forest, C. Statistical calibration of climate system properties. J. R. Stat. Soc. Ser. C (Applied Stat. 58, 485-503 (2009).

200. Tomassini, L. et al. A smoothing algorithm for estimating stochastic, continuous time model parameters and its application to a simple climate model. J. R. Stat. Soc. Ser. C (Applied Stat. 58, 679-704 (2009).

201. Libardoni, A. G. \& Forest, C. E. Sensitivity of distributions of climate system properties to the surface temperature dataset. Geophys. Res. Lett. 38, L22705 (2011).

202. Bengtsson, L. \& Schwartz, S. E. Determination of a lower bound on Earth's climate sensitivity. Tellus B Chem. Phys. Meteorol. 65, 21533 (2013).

203. Schwartz, S. E. Determination of Earth's transient and equilibrium climate sensitivities from observations over the twentieth century: Strong dependence on assumed forcing. Surv. Geophys. 33, 745-777 (2012).

204. Schwartz, S. E., Charlson, R. J., Kahn, R. \& Rodhe, H. Earth's climate sensitivity: Apparent inconsistencies in recent assessments. Earth's Futur. 2, 601-605 (2014).

205. Storelvmo, T., Leirvik, T., Lohmann, U., Phillips, P. C. B. \& Wild, M. Disentangling greenhouse warming and aerosol cooling to reveal Earth's climate sensitivity. Nat. Geosci. 9, 286-289 (2016).

206. Tanaka, K., Raddatz, T., O'Neill, B. C. \& Reick, C. H. Insufficient forcing uncertainty underestimates the risk of high climate sensitivity. Geophys. Res. Lett. 36, L16709 (2009).

207. Tanaka, K. \& Raddatz, T. Correlation between climate sensitivity and aerosol forcing and its implication for the 'climate trap'. Clim. Change 109, 815-825 (2011).

208. Urban, N. M. \& Keller, K. Complementary observational constraints on climate sensitivity. Geophys. Res. Lett. 36, L04708 (2009).

209. Webster, M. et al. Uncertainty analysis of climate change and policy response. Clim. Change 61, 295-320 (2003).

210. Harvey, L. D. D. \& Kaufmann, R. K. Simultaneously constraining climate sensitivity and aerosol radiative forcing. J. Clim. 15, 2837-2861 (2002).

211. Andreae, M. O., Jones, C. D. \& Cox, P. M. Strong present-day aerosol cooling implies a hot future. Nature 435, 1187-1190 (2005).

212. Loehle, C. Global temperature trends adjusted for unforced variability. Univers. J. Geosci. 3, 183-187 (2015).

213. Lewis, N. \& Grünwald, P. Objectively combining AR5 instrumental period and paleoclimate climate sensitivity evidence. Clim. Dyn. 0, 0 (2017). 
214. van Hateren, J. H. A fractal climate response function can simulate global average temperature trends of the modern era and the past millennium. Clim. Dyn. 40, 2651-2670 (2013).

215. van der Werf, G. R. \& Dolman, A. J. Impact of the Atlantic Multidecadal Oscillation (AMO) on deriving anthropogenic warming rates from the instrumental temperature record. Earth Syst. Dyn. 5, 375-382 (2014).

216. Rypdal, M. \& Rypdal, K. Long-memory effects in linear response models of Earth's temperature and implications for future global warming. J. Clim. 27, 5240-5258 (2014).

217. Loutre, M. F. et al. Evaluating climate model performance with various parameter sets using observations over the recent past. Clim. Past 7, 511-526 (2011).

218. Rowlands, D. J. et al. Broad range of $\mathbf{2 0 5 0}$ warming from an observationally constrained large climate model ensemble. Nat. Geosci. 5, 256-260 (2012).

219. Stott, P. A., Huntingford, C., Jones, C. D. \& Kettleborough, J. A. Observed climate change constrains the likelihood of extreme future global warming. Tellus, Ser. B Chem. Phys. Meteorol. 60 B, 76-81 (2008).

220. Stott, P. A. \& Kettleborough, J. A. Origins and estimates of uncertainty in predictions of twenty-first century temperature rise. Nature 416, 723-726 (2002).

221. Gillett, N. P., Arora, V. K., Flato, G. M., Scinocca, J. F. \& von Salzen, K. Improved constraints on 21st-century warming derived using 160 years of temperature observations. Geophys. Res. Lett. 39, L01704 (2012).

222. Stott, P. A. et al. Observational constraints on past attributable warming and predictions of future global warming. J. Clim. 19, 3055-3069 (2006).

223. Gillett, N. P., Arora, V. K., Matthews, D. \& Allen, M. R. Constraining the ratio of global warming to cumulative $\mathrm{CO}_{2}$ emissions using CMIP5 simulations. J. Clim. 26, 6844-6858 (2013).

224. Lewis, N. Implications of recent multimodel attribution studies for climate sensitivity. Clim. Dyn. 46, 1387-1396 (2016).

225. Forster, P. M. Inference of climate sensitivity from analysis of Earth's energy budget. Annu. Rev. Earth Planet. Sci. 44, 85-106 (2016).

226. DelSole, T., Yan, X. \& Tippett, M. K. Inferring aerosol cooling from hydrological sensitivity. J. Clim. 29, 6167-6178 (2016).

227. Millar, R. J. et al. Model structure in observational constraints on transient climate response. Clim. Change 131, 199-211 (2015).

228. Cowtan, K. et al. Robust comparison of climate models with observations using blended land air and ocean sea surface temperatures. Geophys. Res. Lett. 42, 6526-6534 (2015).

229. Huber, M. \& Knutti, R. Anthropogenic and natural warming inferred from changes in Earth's energy balance. Nat. Geosci. 5, 31-36 (2011).

230. Lacis, A. A., Schmidt, G. A., Rind, D. \& Ruedy, R. A. Atmospheric $\mathrm{CO}_{2}$ : principal control knob governing Earth's temperature. Science 330, 356-359 (2010).

231. Murphy, D. M. et al. An observationally based energy balance for the Earth since 1950. J. Geophys. Res. 114, 1-14 (2009).

232. Allan, R. P. et al. Changes in global net radiative imbalance 1985-2012. Geophys. Res. Lett. 41, $1-10$ (2014). 
233. Loeb, N. G. et al. Advances in understanding top-of-atmosphere radiation variability from satellite observations. Surv. Geophys. 33, 359-385 (2012).

234. Stephens, G. L. et al. An update on Earth's energy balance in light of the latest global observations. Nat. Geosci. 5, 691-696 (2012).

235. Loeb, N. G. et al. Observed changes in top-of-the-atmosphere radiation and upper-ocean heating consistent within uncertainty. Nat. Geosci. 5, 110-113 (2012).

236. Kato, S. et al. Detection of atmospheric changes in spatially and temporally averaged infrared spectra observed from space. J. Clim. 24, 6392-6407 (2011).

237. Church, J. A. et al. Revisiting the Earth's sea-level and energy budgets from 1961 to 2008. Geophys. Res. Lett. 38, L18601 (2011).

238. Loeb, N. G. et al. Toward optimal closure of the Earth's top-of-atmosphere radiation budget. J. Clim. 22, 748-766 (2009).

239. Smith, D. M. et al. Earth's energy imbalance since 1960 in observations and CMIP5 models. Geophys. Res. Lett. 42, 1205-1213 (2015).

240. Trenberth, K. E. \& Fasullo, J. T. Tracking Earth's energy: From El Niño to global warming. Surv. Geophys. 33, 413-426 (2011).

241. Trenberth, K. E., Fasullo, J. T. \& Balmaseda, M. A. Earth's energy imbalance. J. Clim. 27, 31293144 (2014).

242. Norris, J. R. et al. Evidence for climate change in the satellite cloud record. Nature 536, 72-75 (2016).

243. He, J., Winton, M., Vecchi, G., Jia, L. \& Rugenstein, M. Transient climate sensitivity depends on base climate ocean circulation. J. Clim. 30, 1493-1504 (2017).

244. Liang, M.-C., Lin, L.-C., Tung, K.-K., Yung, Y. L. \& Sun, S. Transient climate response in coupled atmospheric-ocean general circulation models. J. Atmos. Sci. 70, 1291-1296 (2013).

245. Trossman, D. S., Palter, J. B., Merlis, T. M., Huang, Y. \& Xia, Y. Large-scale ocean circulationcloud interactions reduce the pace of transient climate change. Geophys. Res. Lett. 43, 39353943 (2016).

246. Allen, M. R., Forest, C. E., Stone, P. H. \& Sokolov, A. P. Constraining uncertainties in climate models using climate change detection techniques. Geophys. Res. Lett. 27, 569-572 (2000).

247. Stott, P. A., Kettleborough, J. A. \& Allen, M. R. Uncertainty in continental-scale temperature predictions. Geophys. Res. Lett. 33, L02708 (2006).

248. Rogelj, J., Meinshausen, M. \& Knutti, R. Global warming under old and new scenarios using IPCC climate sensitivity range estimates. Nat. Clim. Chang. 2, 248-253 (2012).

249. Sokolov, A. P. et al. Probabilistic forecast for twenty-first-century climate based on uncertainties in emissions (without policy) and climate parameters. J. Clim. 22, 5175-5204 (2009).

250. Sokolov, A. P., Forest, C. E. \& Stone, P. H. Sensitivity of climate change projections to uncertainties in the estimates of observed changes in deep-ocean heat content. Clim. Dyn. 34, 735-745 (2010).

251. Jones, G. S., Stott, P. A. \& Mitchell, J. F. B. Uncertainties in the attribution of greenhouse gas warming and implications for climate prediction. J. Geophys. Res. Atmos. 121, 6969-6992 (2016). 
252. Kaufmann, R. K. \& Stern, D. I. Cointegration analysis of hemispheric temperature relations. J. Geophys. Res. 107, 4012 (2002).

253. Lovejoy, S. Scaling fluctuation analysis and statistical hypothesis testing of anthropogenic warming. Clim. Dyn. 42, 2339-2351 (2014).

254. Lovejoy, S. \& Schertzer, D. Stochastic and scaling climate sensitivities: Solar, volcanic and orbital forcings. Geophys. Res. Lett. 39, L11702 (2012).

255. Stern, D. I. An atmosphere-ocean time series model of global climate change. Comput. Stat. Data Anal. 51, 1330-1346 (2006).

256. Bell, T. L. Climate sensitivity from fluctuation dissipation - Some simple model tests. Journal of the Atmospheric Sciences 37, 1700-1707 (1980).

257. Ragone, F., Lucarini, V. \& Lunkeit, F. A new framework for climate sensitivity and prediction: A modelling perspective. Clim. Dyn. 46, 1459-1471 (2016).

258. Cooper, F. C. \& Haynes, P. H. Climate sensitivity via a nonparametric fluctuation-dissipation theorem. J. Atmos. Sci. 68, 937-953 (2011).

259. Kirk-Davidoff, D. B. On the diagnosis of climate sensitivity using observations of fluctuations. Atmos. Chem. Phys. 9, 813-822 (2009).

260. Majda, A. J., Gershgorin, B. \& Yuan, Y. Low-frequency climate response and fluctuationdissipation theorems: Theory and practice. J. Atmos. Sci. 67, 1186-1201 (2010).

261. Abramov, R. V. \& Majda, A. J. A new algorithm for low-frequency climate response. J. Atmos. Sci. 66, 286-309 (2009).

262. Leith, C. E. Climate response and fluctuation dissipation. J. Atmos. Sci. 32, 2022-2026 (1975).

263. Thuburn, J. Climate sensitivities via a Fokker-Planck adjoint approach. Q. J. R. Meteorol. Soc. 131, 73-92 (2005).

264. Lucarini, V., Ragone, F. \& Lunkeit, F. Predicting climate change using response theory: Global averages and spatial patterns. J. Stat. Phys. 166, 1036-1064 (2017).

265. Zhou, C., Zelinka, M. D., Dessler, A. E. \& Klein, S. A. The relationship between interannual and long-term cloud feedbacks. Geophys. Res. Lett. 42, 10,463-10,469 (2015).

266. Dessler, A. E., Zhang, Z. \& Yang, P. Water-vapor climate feedback inferred from climate fluctuations, 2003-2008. Geophys. Res. Lett. 35, L20704 (2008).

267. Dessler, A. E. Observations of climate feedbacks over 2000-10 and comparisons to climate models. J. Clim. 26, 333-342 (2013).

268. Tsushima, Y. \& Manabe, S. Assessment of radiative feedback in climate models using satellite observations of annual flux variation. Proc. Natl. Acad. Sci. 110, 7568-7573 (2013).

269. Xie, S.-P., Kosaka, Y. \& Okumura, Y. M. Distinct energy budgets for anthropogenic and natural changes during global warming hiatus. Nat. Geosci. 9, 29-33 (2015).

270. Brown, P. T., Li, W., Jiang, J. H. \& Su, H. Unforced surface air temperature variability and its contrasting relationship with the anomalous TOA energy flux at local and global spatial scales. J. Clim. 29, 925-940 (2016).

271. Lin, B. et al. Estimations of climate sensitivity based on top-of-atmosphere radiation imbalance. Atmos. Chem. Phys. 10, 1923-1930 (2010). 
272. Lin, B., Min, Q., Sun, W., Hu, Y. \& Fan, T.-F. Can climate sensitivity be estimated from shortterm relationships of top-of-atmosphere net radiation and surface temperature? J. Quant. Spectrosc. Radiat. Transf. 112, 177-181 (2011).

273. Trenberth, K. E., Zhang, Y., Fasullo, J. T. \& Taguchi, S. Climate variability and relationships between top-of-atmosphere radiation and temperatures on Earth. J. Geophys. Res. Atmos. 120, 3642-3659 (2015).

274. Masters, T. On the determination of the global cloud feedback from satellite measurements. Earth Syst. Dyn. 3, 97-107 (2012).

275. Trenberth, K. E., Fasullo, J. T. \& Abraham, J. P. Issues in establishing climate sensitivity in recent studies. Remote Sens. 3, 2051-2056 (2011).

276. Lyman, J. M. Estimating global energy flow from the global upper ocean. Surv. Geophys. 33, 387-393 (2011).

277. Abraham, J. Issues related to the use of one-dimensional ocean-diffusion models for determining climate sensitivity. J. Earth Sci. Clim. Change 5, (2014).

278. Murphy, D. M. \& Forster, P. M. On the accuracy of deriving climate feedback parameters from correlations between surface temperature and outgoing radiation. J. Clim. 23, 4983-4988 (2010).

279. Richardson, M., Hausfather, Z., Nuccitelli, D. A., Rice, K. \& Abraham, J. P. Misdiagnosis of Earth climate sensitivity based on energy balance model results. Sci. Bull. 60, 1370-1377 (2015).

280. Lindzen, R. S. \& Choi, Y.-S. On the determination of climate feedbacks from ERBE data. Geophys. Res. Lett. 36, L16705 (2009).

281. Lindzen, R. S. \& Choi, Y.-S. On the observational determination of climate sensitivity and its implications. Asia-Pacific J. Atmos. Sci. 47, 377-390 (2011).

282. Spencer, R. W. \& Braswell, W. D. Potential biases in feedback diagnosis from observational data: A simple model demonstration. J. Clim. 21, 5624-5628 (2008).

283. Spencer, R. W. \& Braswell, W. D. On the diagnosis of radiative feedback in the presence of unknown radiative forcing. J. Geophys. Res. 115, D16109 (2010).

284. Spencer, R. W. \& Braswell, W. D. On the nisdiagnosis of surface temperature feedbacks from variations in Earth's radiant energy balance. Remote Sens. 3, 1603-1613 (2011).

285. Choi, Y.-S. et al. Influence of non-feedback variations of radiation on the determination of climate feedback. Theor. Appl. Climatol. 115, 355-364 (2014).

286. Koumoutsaris, S. What can we learn about climate feedbacks from short-term climate variations? Tellus $A$ 65, 1-17 (2013).

287. Bodman, R. W. \& Jones, R. N. Bayesian estimation of climate sensitivity using observationally constrained simple climate models. Wiley Interdiscip. Rev. Clim. Chang. 7, 461-473 (2016).

288. Chung, E.-S., Soden, B. J. \& Sohn, B.-J. Revisiting the determination of climate sensitivity from relationships between surface temperature and radiative fluxes. Geophys. Res. Lett. 37, L10703 (2010).

289. Murphy, D. M. Constraining climate sensitivity with linear fits to outgoing radiation. Geophys. Res. Lett. 37, L09704 (2010).

290. Monckton, C., Soon, W. W.-H., Legates, D. R. \& Briggs, W. M. Why models run hot: results from an irreducibly simple climate model. Sci. Bull. 60, 122-135 (2015). 
291. Bates, J. R. Estimating climate sensitivity using two-zone energy balance models. Earth Sp. Sci. 3, 207-225 (2016).

292. Bates, J. R. Climate stability and sensitivity in some simple conceptual models. Clim. Dyn. 38, 455-473 (2012).

293. Schwartz, S. E. Reply to comments by G. Foster et al., R. Knutti et al., and N. Scafetta on 'Heat capacity, time constant, and sensitivity of Earth's climate system'. J. Geophys. Res. 113, D15105 (2008).

294. Schwartz, S. E. Heat capacity, time constant, and sensitivity of Earth's climate system. J. Geophys. Res. 112, D24S05 (2007).

295. Foster, G., Annan, J. D., Schmidt, G. A. \& Mann, M. E. Comment on 'Heat capacity, time constant, and sensitivity of Earth's climate system' by S. E. Schwartz. J. Geophys. Res. 113, D15102 (2008).

296. Schwartz, S. E. Uncertainty in climate sensitivity: Causes, consequences, challenges. Energy Environ. Sci. 1, 430-453 (2008).

297. Chylek, P. et al. Limits on climate sensitivity derived from recent satellite and surface observations. J. Geophys. Res. 112, D24S04 (2007).

298. Trenberth, K. E., Fasullo, J. T., O'Dell, C. \& Wong, T. Relationships between tropical sea surface temperature and top-of-atmosphere radiation. Geophys. Res. Lett. 37, L03702 (2010).

299. Loehle, C. A minimal model for estimating climate sensitivity. Ecol. Modell. 276, 80-84 (2014).

300. Cawley, G. C., Cowtan, K., Way, R. G., Jacobs, P. \& Jokim?ki, A. On a minimal model for estimating climate sensitivity. Ecol. Modell. 297, 20-25 (2015).

301. Ollila, A. The Potency of Carbon Dioxide $\left(\mathrm{CO}_{2}\right)$ as a Greenhouse Gas. Dev. Earth Sci. 2, (2014).

302. Soden, B. J. Global cooling after the eruption of Mount Pinatubo: A test of climate feedback by water vapor. Science 296, 727-730 (2002).

303. Bender, F. A.-M., Ekman, A. M. L. \& Rodhe, H. Response to the eruption of Mount Pinatubo in relation to climate sensitivity in the CMIP3 models. Clim. Dyn. 35, 875-886 (2010).

304. Merlis, T. M., Held, I. M., Stenchikov, G. L., Zeng, F. \& Horowitz, L. W. Constraining transient climate sensitivity using coupled climate model simulations of volcanic eruptions. J. Clim. 140731121655006 (2014). doi:10.1175/JCLI-D-14-00214.1

305. Wigley, T. M. L. Effect of climate sensitivity on the response to volcanic forcing. J. Geophys. Res. 110, D09107 (2005).

306. Boer, G. J., Stowasser, M. \& Hamilton, K. Inferring climate sensitivity from volcanic events. Clim. Dyn. 28, 481-502 (2007).

307. Yokohata, T. et al. Climate response to volcanic forcing: Validation of climate sensitivity of a coupled atmosphere-ocean general circulation model. Geophys. Res. Lett. 32, L21710 (2005).

308. Santer, B. et al. Volcanic effects on climate. Nat. Clim. Chang. 6, 3-4 (2015).

309. Ollila, A. Climate sensitivity parameter in the test of the Mount Pinatubo eruption. Phys. Sci. Int. J. 9, 1-14 (2016).

310. Lehner, F., Schurer, A. P., Hegerl, G. C., Deser, C. \& Frölicher, T. L. The importance of ENSO phase during volcanic eruptions for detection and attribution. Geophys. Res. Lett. 43, 28512858 (2016). 
311. Douglass, D. H., Knox, R. S., Pearson, B. D. \& Clark, A. Thermocline flux exchange during the Pinatubo event. Geophys. Res. Lett. 33, L19711 (2006).

312. Tung, K. K., Zhou, J. \& Camp, C. D. Constraining model transient climate response using independent observations of solar-cycle forcing and response. Geophys. Res. Lett. 35, L17707 (2008).

313. Raper, S. C. B., Gregory, J. M. \& Stouffer, R. J. The role of climate sensitivity and ocean heat uptake on AOGCM transient temperature response. J. Clim. 15, 124-130 (2002).

314. Räisänen, J. Probability distributions of $\mathrm{CO}_{2}$-induced global warming as inferred directly from multimodel ensemble simulations. Geophysica 41, 19-30 (2005).

315. Forster, P. M. et al. Evaluating adjusted forcing and model spread for historical and future scenarios in the CMIP5 generation of climate models. J. Geophys. Res. Atmos. 118, 1139-1150 (2013).

316. Knutti, R. Why are climate models reproducing the observed global surface warming so well? Geophys. Res. Lett. 35, L18704 (2008).

317. Kiehl, J. T. Twentieth century climate model response and climate sensitivity. Geophys. Res. Lett. 34, L22710 (2007).

318. Bony, S. et al. How well do we understand and evaluate climate change feedback processes? J. Clim. 19, 3445-3482 (2006).

319. Soden, B. J. \& Held, I. M. An assessment of climate feedbacks in coupled ocean-atmosphere models. J. Clim. 19, 3354-3360 (2006).

320. Huybers, P. Compensation between model feedbacks and curtailment of climate sensitivity. J. Clim. 23, 3009-3018 (2010).

321. Whetton, P., Macadam, I., Bathols, J. \& O'Grady, J. Assessment of the use of current climate patterns to evaluate regional enhanced greenhouse response patterns of climate models. Geophys. Res. Lett. 34, 1-5 (2007).

322. Scherrer, S. C. Present-day interannual variability of surface climate in CMIP3 models and its relation to future warming. Int. J. Climatol. 31, 1518-1529 (2011).

323. Knutti, R., Furrer, R., Tebaldi, C., Cermak, J. \& Meehl, G. A. Challenges in combining projections from multiple climate models. J. Clim. 23, 2739-2758 (2010).

324. Masson, D. \& Knutti, R. Predictor screening, calibration, and observational constraints in climate model ensembles: An illustration using climate sensitivity. J. Clim. 26, 887-898 (2013).

325. Sanderson, B. M. On the estimation of systematic error in regression-based predictions of climate sensitivity. Clim. Change 118, 757-770 (2013).

326. Knutti, R., Meehl, G. A., Allen, M. R. \& Stainforth, D. A. Constraining climate sensitivity from the seasonal cycle in surface temperature. J. Clim. 19, 4224-4233 (2006).

327. Reichler, T. \& Kim, J. How well do coupled models simulate today's climate? Bull. Am. Meteorol. Soc. 89, 303 (2008).

328. Knutti, R., Masson, D. \& Gettelman, A. Climate model genealogy: Generation CMIP5 and how we got there. Geophys. Res. Lett. 40, 1194-1199 (2013).

329. Sanderson, B. M. \& Knutti, R. On the interpretation of constrained climate model ensembles. Geophys. Res. Lett. 39, L16708 (2012). 
330. Hall, A. \& Qu, X. Using the current seasonal cycle to constrain snow albedo feedback in future climate change. Geophys. Res. Lett. 33, L03502 (2006).

331. Boé, J., Hall, A. \& Qu, X. September sea-ice cover in the Arctic Ocean projected to vanish by 2100. Nat. Geosci. 2, 341-343 (2009).

332. Mahlstein, I. \& Knutti, R. September Arctic sea ice predicted to disappear near $2^{\circ} \mathrm{C}$ global warming above present. J. Geophys. Res. 117, D06104 (2012).

333. Sanderson, B. M. et al. Constraints on model response to greenhouse gas forcing and the role of subgrid-scale processes. J. Clim. 21, 2384-2400 (2008).

334. Sanderson, B. M., Piani, C., Ingram, W. J., Stone, D. A. \& Allen, M. R. Towards constraining climate sensitivity by linear analysis of feedback patterns in thousands of perturbed-physics GCM simulations. Clim. Dyn. 30, 175-190 (2008).

335. Piani, C., Frame, D. J., Stainforth, D. A. \& Allen, M. R. Constraints on climate change from a multi-thousand member ensemble of simulations. Geophys. Res. Lett. 32, L23825 (2005).

336. Stainforth, D. A. et al. Uncertainty in predictions of the climate response to rising levels of greenhouse gases. Nature 433, 403-406 (2005).

337. Huber, M., Mahlstein, I., Wild, M., Fasullo, J. \& Knutti, R. Constraints on climate sensitivity from radiation patterns in climate models. J. Clim. 24, 1034-1052 (2011).

338. Klocke, D., Pincus, R. \& Quaas, J. On constraining estimates of climate sensitivity with presentday observations through model weighting. J. Clim. 24, 6092-6099 (2011).

339. Fasullo, J. T. \& Trenberth, K. E. A less cloudy future: The role of subtropical subsidence in climate sensitivity. Science 338, 792-794 (2012).

340. Shukla, J., DelSole, T., Fennessy, M., Kinter, J. \& Paolino, D. Climate model fidelity and projections of climate change. Geophys. Res. Lett. 33, L07702 (2006).

341. Tett, S. F. B., Rowlands, D. J., Mineter, M. J. \& Cartis, C. Can top-of-atmosphere radiation measurements constrain climate predictions? Part II: Climate sensitivity. J. Clim. 26, 93679383 (2013).

342. Tett, S. F. B., Mineter, M. J., Cartis, C., Rowlands, D. J. \& Liu, P. Can top-of-atmosphere radiation measurements constrain climate predictions? Part I: Tuning. J. Clim. 26, 9348-9366 (2013).

343. Sherwood, S. C., Bony, S. \& Dufresne, J.-L. Spread in model climate sensitivity traced to atmospheric convective mixing. Nature 505, 37-42 (2014).

344. Zhai, C., Jiang, J. H. \& Su, H. Long-term cloud change imprinted in seasonal cloud variation: More evidence of high climate sensitivity. Geophys. Res. Lett. 42, 8729-8737 (2015).

345. Tian, B. Spread of model climate sensitivity linked to double-Intertropical Convergence Zone bias. Geophys. Res. Lett. 42, 4133-4141 (2015).

346. Tan, I., Storelvmo, T. \& Zelinka, M. D. Observational constraints on mixed-phase clouds imply higher climate sensitivity. Science 352, 224-227 (2016).

347. Brient, F. \& Schneider, T. Constraints on climate sensitivity from space-based measurements of low-cloud reflection. J. Clim. 29, 5821-5835 (2016).

348. Kamae, Y., Ogura, T., Shiogama, H. \& Watanabe, M. Recent progress toward reducing the uncertainty in tropical low cloud feedback and climate sensitivity: A review. Geosci. Lett. 3, 110 (2016). 
349. Volodin, E. M. Relation between temperature sensitivity to doubled carbon dioxide and the distribution of clouds in current climate models. Izv. Atmos. Ocean. Phys. 44, 288-299 (2008).

350. Trenberth, K. E. \& Fasullo, J. T. Simulation of present-day and twenty-first-century energy budgets of the Southern Oceans. J. Clim. 23, 440-454 (2010).

351. Su, H. et al. Weakening and strengthening structures in the Hadley Circulation change under global warming and implications for cloud response and climate sensitivity. J. Geophys. Res. Atmos. 119, 5787-5805 (2014).

352. Levis, S., Bonan, G. B. \& Lawrence, P. J. Present-day springtime high-latitude surface albedo as a predictor of simulated climate sensitivity. Geophys. Res. Lett. 34, L17703 (2007).

353. Tsushima, Y., Abe-Ouchi, A. \& Manabe, S. Radiative damping of annual variation in global mean surface temperature: comparison between observed and simulated feedback. Clim. Dyn. 24, 591-597 (2005).

354. Wu, Q. Statistics of calendar month averages of surface temperature: A possible relationship to climate sensitivity. J. Geophys. Res. 108, 4071 (2003).

355. Sexton, D. M. H. \& Murphy, J. M. Multivariate probabilistic projections using imperfect climate models. Part II: Robustness of methodological choices and consequences for climate sensitivity. Clim. Dyn. 38, 2543-2558 (2012).

356. Siler, N., Po-Chedley, S. \& Bretherton, C. S. Variability in modeled cloud feedback tied to differences in the climatological spatial pattern of clouds. Clim. Dyn. 1-12 (2017). doi:10.1007/s00382-017-3673-2

357. Gordon, N. D. \& Klein, S. A. Low-cloud optical depth feedback in climate models. J. Geophys. Res. Atmos. 119, 6052-6065 (2014).

358. Gettelman, A. \& Sherwood, S. C. Processes responsible for cloud feedback. Curr. Clim. Chang. Reports (2016). doi:10.1007/s40641-016-0052-8

359. Bretherton, C. S. Insights into low-latitude cloud feedbacks from high-resolution models. Philos. Trans. R. Soc. A Math. Phys. Eng. Sci. 373, 20140415 (2015).

360. Clement, A. C., Burgman, R. \& Norris, J. R. Observational and model evidence for positive lowlevel cloud feedback. Science 325, 460-464 (2009).

361. Lemoine, D. M. Climate sensitivity distributions dependence on the possibility that models share biases. J. Clim. 23, 4395-4415 (2010).

362. Hourdin, F. et al. The art and science of climate model tuning. Bull. Am. Meteorol. Soc. 98, 589-602 (2017).

363. Schmidt, G. A. et al. Practice and philosophy of climate model tuning across six U.S. modeling centers. Geosci. Model Dev. Discuss. 1-24 (2017). doi:10.5194/gmd-2017-30

364. Grise, K. M., Polvani, L. M. \& Fasullo, J. T. Reexamining the relationship between climate sensitivity and the Southern Hemisphere radiation budget in CMIP models. J. Clim. 28, 92989312 (2015).

365. Caldwell, P. M. et al. Statistical significance of climate sensitivity predictors obtained by data mining. Geophys. Res. Lett. 41, 1803-1808 (2014).

366. Sanderson, B. M. A multimodel study of parametric uncertainty in predictions of climate response to rising greenhouse gas concentrations. J. Clim. 24, 1362-1377 (2011).

367. Sanderson, B. M., Shell, K. M. \& Ingram, W. Climate feedbacks determined using radiative 
kernels in a multi-thousand member ensemble of AOGCMs. Clim. Dyn. 35, 1219-1236 (2009).

368. Rodwell, M. J. \& Palmer, T. Using numerical weather prediction to assess climate models. Q. J. R. Meteorol. Soc. 133, 129-146 (2007).

369. Zhao, M. et al. Uncertainty in model climate sensitivity traced to representations of cumulus precipitation microphysics. J. Clim. 29, 543-560 (2016).

370. Dufresne, J.-L. \& Bony, S. An assessment of the primary sources of spread of global warming estimates from coupled atmosphere-ocean models. J. Clim. 21, 5135 (2008).

371. Soden, B. J. et al. Quantifying climate feedbacks using radiative kernels. J. Clim. 21, 3504-3520 (2008).

372. Medeiros, B. et al. Aquaplanets, climate sensitivity, and low clouds. J. Clim. 21, 4974-4991 (2008).

373. Bony, S. et al. Thermodynamic control of anvil cloud amount. Proc. Natl. Acad. Sci. 113, 89278932 (2016).

374. Qu, X., Hall, A., Klein, S. A. \& Caldwell, P. M. On the spread of changes in marine low cloud cover in climate model simulations of the 21st century. Clim. Dyn. 42, 2603-2626 (2014).

375. Webb, M. J., Lambert, F. H. \& Gregory, J. M. Origins of differences in climate sensitivity, forcing and feedback in climate models. Clim. Dyn. 40, 677-707 (2013).

376. Tomassini, L., Voigt, A. \& Stevens, B. On the connection between tropical circulation, convective mixing, and climate sensitivity. Q. J. R. Meteorol. Soc. 141, 1404-1416 (2015).

377. Vial, J., Dufresne, J.-L. \& Bony, S. On the interpretation of inter-model spread in CMIP5 climate sensitivity estimates. Clim. Dyn. 41, 3339-3362 (2013).

378. Bony, S. Marine boundary layer clouds at the heart of tropical cloud feedback uncertainties in climate models. Geophys. Res. Lett. 32, L20806 (2005).

379. Bony, S. et al. Clouds, circulation and climate sensitivity. Nat. Geosci. 8, 261-268 (2015).

380. Parker, W. S. Understanding pluralism in climate modeling. Found. Sci. 11, 349-368 (2006).

381. Pincus, R., Batstone, C. P., Hofmann, R. J. P., Taylor, K. E. \& Glecker, P. J. Evaluating the present-day simulation of clouds, precipitation, and radiation in climate models. J. Geophys. Res. 113, 1-10 (2008).

382. Gleckler, P. J., Taylor, K. E. \& Doutriaux, C. Performance metrics for climate models. J. Geophys. Res. 113, 1-20 (2008).

383. Knutti, R. et al. Good Practice Guidance Paper on Assessing and Combining Multi Model Climate Projections. Meeting Report of the Intergovernmental Panel on Climate Change Expert Meeting on Assessing and Combining Multi Model Climate Projections (IPCC Working Group I Technical Support Unit, University of Bern, Bern, Switzerland, 2010).

384. Pierce, D. W., Barnett, T. P., Santer, B. D. \& Gleckler, P. J. Selecting global climate models for regional climate change studies. Proc. Natl. Acad. Sci. U. S. A. 106, 8441-8446 (2009).

385. Eyring, V. et al. A strategy for process-oriented validation of coupled chemistry-climate models. Bull. Am. Meteorol. Soc. 86, 1117-1133 (2005).

386. Wenzel, S., Eyring, V., Gerber, E. P. \& Karpechko, A. Y. Constraining future summer austral jet stream positions in the CMIP5 Ensemble by process-oriented multiple diagnostic regression. $J$. Clim. 29, 673-687 (2016). 
387. Borodina, A., Fischer, E. M. \& Knutti, R. Emergent Constraints in Climate Projections: A Case Study of Changes in High-Latitude Temperature Variability. J. Clim. 30, 3655-3670 (2017).

388. Sanderson, B. M., Knutti, R. \& Caldwell, P. A representative democracy to reduce interdependency in a multimodel ensemble. J. Clim. 28, 5171-5194 (2015).

389. Knutti, R. et al. A climate model projection weighting scheme accounting for performance and interdependence. Geophys. Res. Lett. 1-10 (2017). doi:10.1002/2016GL072012

390. Sanderson, B. M., Wehner, M. \& Knutti, R. Skill and independence weighting for multi-model assessments. Geosci. Model Dev. 10, 2379-2395 (2017).

391. Masson, D. \& Knutti, R. Climate model genealogy. Geophys. Res. Lett. 38, L08703 (2011).

392. Jun, M., Knutti, R. \& Nychka, D. W. Local eigenvalue analysis of CMIP3 climate model errors. Tellus A 60, 992-1000 (2008).

393. Annan, J. D. \& Hargreaves, J. C. Understanding the CMIP3 multimodel ensemble. J. Clim. 24, 4529-4538 (2011).

394. Bishop, C. H. \& Abramowitz, G. Climate model dependence and the replicate Earth paradigm. Clim. Dyn. 41, 885-900 (2012).

395. Abramowitz, G. \& Bishop, C. H. Climate Model Dependence and the Ensemble Dependence Transformation of CMIP Projections. J. Clim. 28, 2332-2348 (2015).

396. Abramowitz, G. \& Gupta, H. Toward a model space and model independence metric. Geophys. Res. Lett. 35, 1-4 (2008).

397. DelSole, T. \& Shukla, J. Artificial skill due to predictor screening. J. Clim. 22, 331-345 (2009).

398. Räisänen, J., Ruokolainen, L. \& Ylhäisi, J. Weighting of model results for improving best estimates of climate change. Clim. Dyn. 35, 407-422 (2009).

399. Weigel, A. P., Knutti, R., Liniger, M. A. \& Appenzeller, C. Risks of model weighting in multimodel climate projections. J. Clim. 23, 4175-4191 (2010).

400. Edwards, T. L., Crucifix, M. \& Harrison, S. P. Using the past to constrain the future: how the palaeorecord can improve estimates of global warming. Prog. Phys. Geogr. 31, 481-500 (2007).

401. Harrison, S. P. et al. Evaluation of CMIP5 palaeo-simulations to improve climate projections. Nat. Clim. Chang. 5, 735-743 (2015).

402. Braconnot, P. et al. Evaluation of climate models using palaeoclimatic data. Nat. Clim. Chang. 2, 417-424 (2012).

403. Schmidt, G. A. et al. Using palaeo-climate comparisons to constrain future projections in CMIP5. Clim. Past 10, 221-250 (2014).

404. Dowsett, H. J. et al. Assessing confidence in Pliocene sea surface temperatures to evaluate predictive models. Nat. Clim. Chang. 2, 365-371 (2012).

405. Lunt, D. J. et al. Warm climates of the past - a lesson for the future? Philos. Trans. R. Soc. A Math. Phys. Eng. Sci. 371, 20130146-20130146 (2013).

406. Schneider von Deimling, T., Held, H., Ganopolski, A. \& Rahmstorf, S. Climate sensitivity estimated from ensemble simulations of glacial climate. Clim. Dyn. 27, 149-163 (2006).

407. Hargreaves, J. C., Abe-Ouchi, A. \& Annan, J. D. Linking glacial and future climates through an 
ensemble of GCM simulations. Clim. Past 3, 77-87 (2007).

408. Hargreaves, J. C., Annan, J. D., Yoshimori, M. \& Abe-Ouchi, A. Can the Last Glacial Maximum constrain climate sensitivity? Geophys. Res. Lett. 39, L24702 (2012).

409. Hopcroft, P. O. \& Valdes, P. J. How well do simulated last glacial maximum tropical temperatures constrain equilibrium climate sensitivity? Geophys. Res. Lett. 42, 5533-5539 (2015).

410. Schmittner, A. et al. Climate sensitivity estimated from temperature reconstructions of the Last Glacial Maximum. Science 334, 1385-1388 (2011).

411. Annan, J. D., Hargreaves, J. C., Ohgaito, R., Abe-Ouchi, A. \& Emori, S. Efficiently constraining climate sensitivity with ensembles of paleoclimate simulations. SOLA 1, 181-184 (2005).

412. Annan, J. D. \& Hargreaves, J. C. A perspective on model-data surface temperature comparison at the Last Glacial Maximum. Quat. Sci. Rev. 107, 1-10 (2015).

413. Köhler, P. et al. What caused Earth's temperature variations during the last 800,000 years? Data-based evidence on radiative forcing and constraints on climate sensitivity. Quat. Sci. Rev. 29, 129-145 (2010).

414. Friedrich, T., Timmermann, A., Tigchelaar, M., Elison Timm, O. \& Ganopolski, A. Nonlinear climate sensitivity and its implications for future greenhouse warming. Sci. Adv. 2, e1501923 (2016).

415. Came, R. E. et al. Coupling of surface temperatures and atmospheric $\mathrm{CO}_{2}$ concentrations during the Palaeozoic era. Nature 449, 198-201 (2007).

416. Crucifix, M. Does the Last Glacial Maximum constrain climate sensitivity? Geophys. Res. Lett. 33, L18701 (2006).

417. Holden, P. B., Edwards, N. R., Oliver, K. I. C., Lenton, T. M. \& Wilkinson, R. D. A probabilistic calibration of climate sensitivity and terrestrial carbon change in GENIE-1. Clim. Dyn. 35, 785806 (2010).

418. Lea, D. W. The 100000 -yr cycle in tropical SST, greenhouse gorcing, and climate sensitivity. J. Clim. 17, 2170-2179 (2004).

419. Manabe, S. \& Broccoli, A. A comparison of climate model sensitivity with data from the last glacial maximum. J. Atmos. Sci. 42, 2643-2651 (1985).

420. Skinner, L. A long view on climate sensitivity. Science 337, 917-919 (2012).

421. Chylek, P. \& Lohmann, U. Aerosol radiative forcing and climate sensitivity deduced from the Last Glacial Maximum to Holocene transition. Geophys. Res. Lett. 35, L04804 (2008).

422. Hargreaves, J. C. \& Annan, J. D. Comment on 'Aerosol radiative forcing and climate sensitivity deduced from the Last Glacial Maximum to Holocene transition', by P. Chylek and U. Lohmann, Geophys. Res. Lett., 2008. Clim. Past 5, 143-145 (2009).

423. Ganopolski, A. \& Schneider von Deimling, T. Comment on 'Aerosol radiative forcing and climate sensitivity deduced from the Last Glacial Maximum to Holocene transition' by Petr Chylek and Ulrike Lohmann. Geophys. Res. Lett. 35, L23703 (2008).

424. Chylek, P. \& Lohmann, U. Reply to comment by Andrey Ganopolski and Thomas Schneider von Deimling on 'Aerosol radiative forcing and climate sensitivity deduced from the Last Glacial Maximum to Holocene transition'. Geophys. Res. Lett. 35, L23704 (2008).

425. Dunkley Jones, T. et al. A Palaeogene perspective on climate sensitivity and methane hydrate 
instability. Philos. Trans. R. Soc. A Math. Phys. Eng. Sci. 368, 2395-2415 (2010).

426. Rohling, E. J., Medina-Elizalde, M., Shepherd, J. G., Siddall, M. \& Stanford, J. D. Sea Surface and High-Latitude Temperature Sensitivity to Radiative Forcing of Climate over Several Glacial Cycles. J. Clim. 25, 1635-1656 (2012).

427. Shaffer, G., Huber, M., Rondanelli, R. \& Pepke Pedersen, J. O. Deep time evidence for climate sensitivity increase with warming. Geophys. Res. Lett. 43, 6538-6545 (2016).

428. Kutzbach, J. E., He, F., Vavrus, S. J. \& Ruddiman, W. F. The dependence of equilibrium climate sensitivity on climate state: Applications to studies of climates colder than present. Geophys. Res. Lett. 40, 3721-3726 (2013).

429. Köhler, P., de Boer, B., von der Heydt, A. S., Stap, L. B. \& van de Wal, R. S. W. On the state dependency of the equilibrium climate sensitivity during the last 5 million years. Clim. Past 11, 1801-1823 (2015).

430. Royer, D. L., Pagani, M. \& Beerling, D. J. Geobiological constraints on Earth system sensitivity to $\mathrm{CO}_{2}$ during the Cretaceous and Cenozoic. Geobiology 10, 298-310 (2012).

431. Caballero, R. \& Huber, M. State-dependent climate sensitivity in past warm climates and its implications for future climate projections. Proc. Natl. Acad. Sci. 110, 14162-14167 (2013).

432. Royer, D. L., Berner, R. A. \& Park, J. Climate sensitivity constrained by $\mathrm{CO}_{2}$ concentrations over the past 420 million years. Nature 446, 530-532 (2007).

433. Anagnostou, E. et al. Changing atmospheric $\mathrm{CO}_{2}$ concentration was the primary driver of early Cenozoic climate. Nature 533, 380-384 (2016).

434. Martínez-Botí, M. a. et al. Plio-Pleistocene climate sensitivity evaluated using high-resolution $\mathrm{CO}_{2}$ records. Nature 518, 49-54 (2015).

435. Goelzer, H. et al. Impact of Greenland and Antarctic ice sheet interactions on climate sensitivity. Clim. Dyn. 37, 1005-1018 (2011).

436. Swingedouw, D. et al. Antarctic ice-sheet melting provides negative feedbacks on future climate warming. Geophys. Res. Lett. 35, 1-4 (2008).

437. Lunt, D. J. et al. Earth system sensitivity inferred from Pliocene modelling and data. Nat. Geosci. 3, 60-64 (2010).

438. Pagani, M., Liu, Z., LaRiviere, J. \& Ravelo, A. C. High Earth-system climate sensitivity determined from Pliocene carbon dioxide concentrations. Nat. Geosci. 3, 27-30 (2010).

439. Hansen, J., Sato, M., Russell, G. \& Kharecha, P. Climate sensitivity, sea level and atmospheric carbon dioxide. Philos. Trans. A. Math. Phys. Eng. Sci. 371, 20120294 (2013).

440. Zeebe, R. E. Time-dependent climate sensitivity and the legacy of anthropogenic greenhouse gas emissions. Proc. Natl. Acad. Sci. 110, 13739-13744 (2013).

441. Kiehl, J. Lessons from Earth's s past. Science 331, 158-159 (2011).

442. Previdi, M. et al. Climate sensitivity in the Anthropocene. Q. J. R. Meteorol. Soc. 139, 11211131 (2013).

443. Dyez, K. A. \& Ravelo, A. C. Late Pleistocene tropical Pacific temperature sensitivity to radiative greenhouse gas forcing. Geology 41, 23-26 (2013).

444. Hansen, J. et al. Target atmospheric $\mathrm{CO}_{2}$ : Where should humanity aim? Open Atmos. Sci. J. 2, 217-231 (2008). 
445. Park, J. \& Royer, D. L. Geologic constraints on the glacial amplification of Phanerozoic climate sensitivity. Am. J. Sci. 311, 1-26 (2011).

446. von der Heydt, A. S. et al. Lessons on climate sensitivity from past climate changes. Curr. Clim. Chang. Reports 2, 148-158 (2016).

447. Morgan, M. G. \& Keith, D. W. Subjective judgements by climate experts. Environ. Sci. Technol. 29, 468-476 (1995).

448. Zickfeld, K., Morgan, M. G., Frame, D. J. \& Keith, D. W. Expert judgments about transient climate response to alternative future trajectories of radiative forcing. Proc. Natl. Acad. Sci. 107, 12451-12456 (2010).

449. Millner, A., Calel, R., Stainforth, D. A. \& MacKerron, G. Do probabilistic expert elicitations capture scientists' uncertainty about climate change? Clim. Change 116, 427-436 (2013).

450. Oppenheimer, M., Little, C. M. \& Cooke, R. M. Expert judgement and uncertainty quantification for climate change. Nat. Clim. Chang. 6, 445-451 (2016).

451. Raupach, M. R. The exponential eigenmodes of the carbon-climate system, and their implications for ratios of responses to forcings. Earth Syst. Dyn. 4, 31-49 (2013).

452. Raupach, M. R. et al. The relationship between peak warming and cumulative $\mathrm{CO}_{2}$ emissions, and its use to quantify vulnerabilities in the carbon-climate-human system. Tellus $B 63,145-$ 164 (2011).

453. Friedlingstein, P. et al. Persistent growth of $\mathrm{CO}_{2}$ emissions and implications for reaching climate targets. Nat. Geosci. 7, 709-715 (2014).

454. MacDougall, A. H. The transient response to cumulative $\mathrm{CO} 2$ emissions: A review. Curr. Clim. Chang. Reports 2, 39-47 (2016).

455. Zickfeld, K., MacDougall, A. H. \& Matthews, H. D. On the proportionality between global temperature change and cumulative $\mathrm{CO}_{2}$ emissions during periods of net negative $\mathrm{CO}_{2}$ emissions. Environ. Res. Lett. 11, 55006 (2016).

456. Matthews, H. D., Gillett, N. P., Stott, P. A. \& Zickfeld, K. The proportionality of global warming to cumulative carbon emissions. Nature 459, 829-832 (2009).

457. Zickfeld, K., Eby, M., Matthews, H. D. \& Weaver, A. J. Setting cumulative emissions targets to reduce the risk of dangerous climate change. Proc. Natl. Acad. Sci. U. S. A. 106, 16129-16134 (2009).

458. Allen, M. R. et al. Warming caused by cumulative carbon emissions towards the trillionth tonne. Nature 458, 1163-1166 (2009).

459. Gregory, J. M., Jones, C. D., Cadule, P. \& Friedlingstein, P. Quantifying carbon cycle feedbacks. J. Clim. 22, 5232-5250 (2009).

460. Steinacher, M., Joos, F. \& Stocker, T. F. Allowable carbon emissions lowered by multiple climate targets. Nature 499, 197-201 (2013).

461. Steinacher, M. \& Joos, F. Transient Earth system responses to cumulative carbon dioxide emissions: Linearities, uncertainties, and probabilities in an observation-constrained model ensemble. Biogeosciences 13, 1071-1103 (2016).

462. Tokarska, K. B., Gillett, N. P., Weaver, A. J., Arora, V. K. \& Eby, M. The climate response to five trillion tonnes of carbon. Nat. Clim. Chang. 6, 851-855 (2016).

463. Williams, R. G., Goodwin, P., Roussenov, V. M. \& Bopp, L. A framework to understand the 
transient climate response to emissions. Environ. Res. Lett. 11, 15003 (2016).

464. Frölicher, T. L., Winton, M. \& Sarmiento, J. L. Continued global warming after $\mathrm{CO}_{2}$ emissions stoppage. Nat. Clim. Chang. 4, 40-44 (2013).

465. Gillett, N. P., Arora, V. K., Zickfeld, K., Marshall, S. J. \& Merryfield, W. J. Ongoing climate change following a complete cessation of carbon dioxide emissions. Nat. Geosci. 4, 83-87 (2011).

466. Solomon, S., Plattner, G.-K., Knutti, R. \& Friedlingstein, P. Irreversible climate change due to carbon dioxide emissions. Proc. Natl. Acad. Sci. 106, 1704-1709 (2009).

467. Solomon, S. et al. Persistence of climate changes due to a range of greenhouse gases. Proc. Natl. Acad. Sci. 107, 18354-18359 (2010).

468. Ehlert, D. \& Zickfeld, K. What determines the warming commitment after cessation of $\mathrm{CO}_{2}$ emissions? Environ. Res. Lett. 12, 15002 (2017).

469. Zickfeld, K., Arora, V. K. \& Gillett, N. P. Is the climate response to $\mathrm{CO}_{2}$ emissions path dependent? Geophys. Res. Lett. 39, 1-6 (2012). 


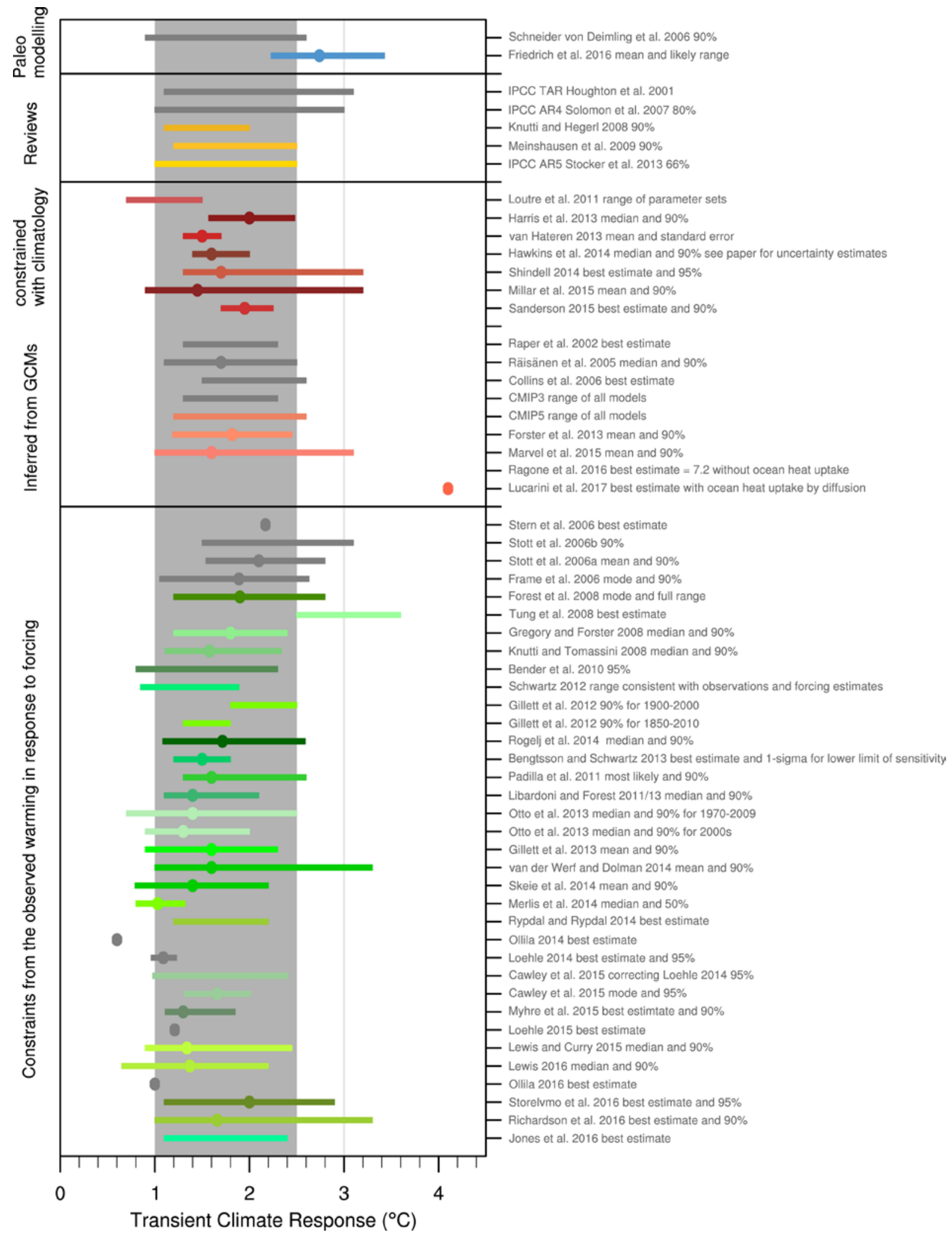

Figure 1: Overview of published best estimates and ranges for the transient climate response constrained by different lines of evidence. Colors indicate different studies. Dots mark means, medians or best estimates, lines mark different percentile ranges. The grey shaded range marks the $1-2.5^{\circ} \mathrm{C}$ range within which TCR is assessed by IPCC to 'likely' lie (probability $>66 \%$ ), the grey vertical line indicates a value of $3^{\circ} \mathrm{C}$ above which TCR is 'extremely unlikely' ( $\left.<5 \%\right)$. Details and assumptions are given in the text, Methods section and the online supplementary table. 


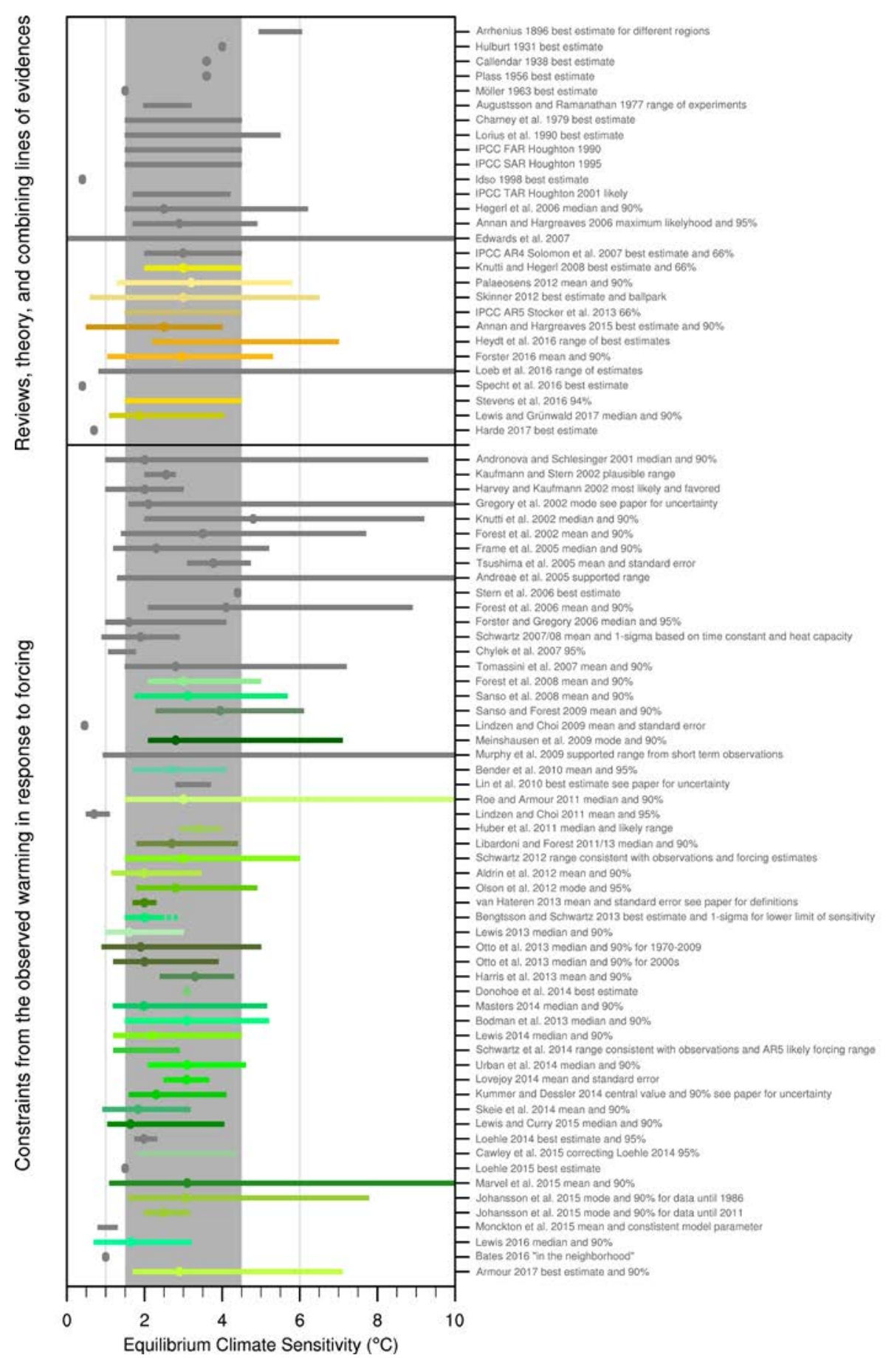

Figure 2: Overview of published best estimates and ranges for equilibrium climate sensitivity constrained by different lines of evidence. Different colors indicate different studies. Dots mark means, medians or best estimates, lines mark different percentile ranges. The grey shaded range marks the $1.5-4.5^{\circ} \mathrm{C}$ range within which ECS is assessed by IPCC to 'likely' lie (probability $>66 \%$ ), the grey vertical lines indicate a value of $1^{\circ} \mathrm{C}$ below which ECS is 'extremely unlikely' $(<5 \%)$, and a value of $6^{\circ} \mathrm{C}$ above which ECS is 'very unlikely' $(<10 \%)$. Details and assumptions are given in the text, Methods section and the online supplementary table. Supplementary figure S1 provides a combination of Figures 2 and 3. 


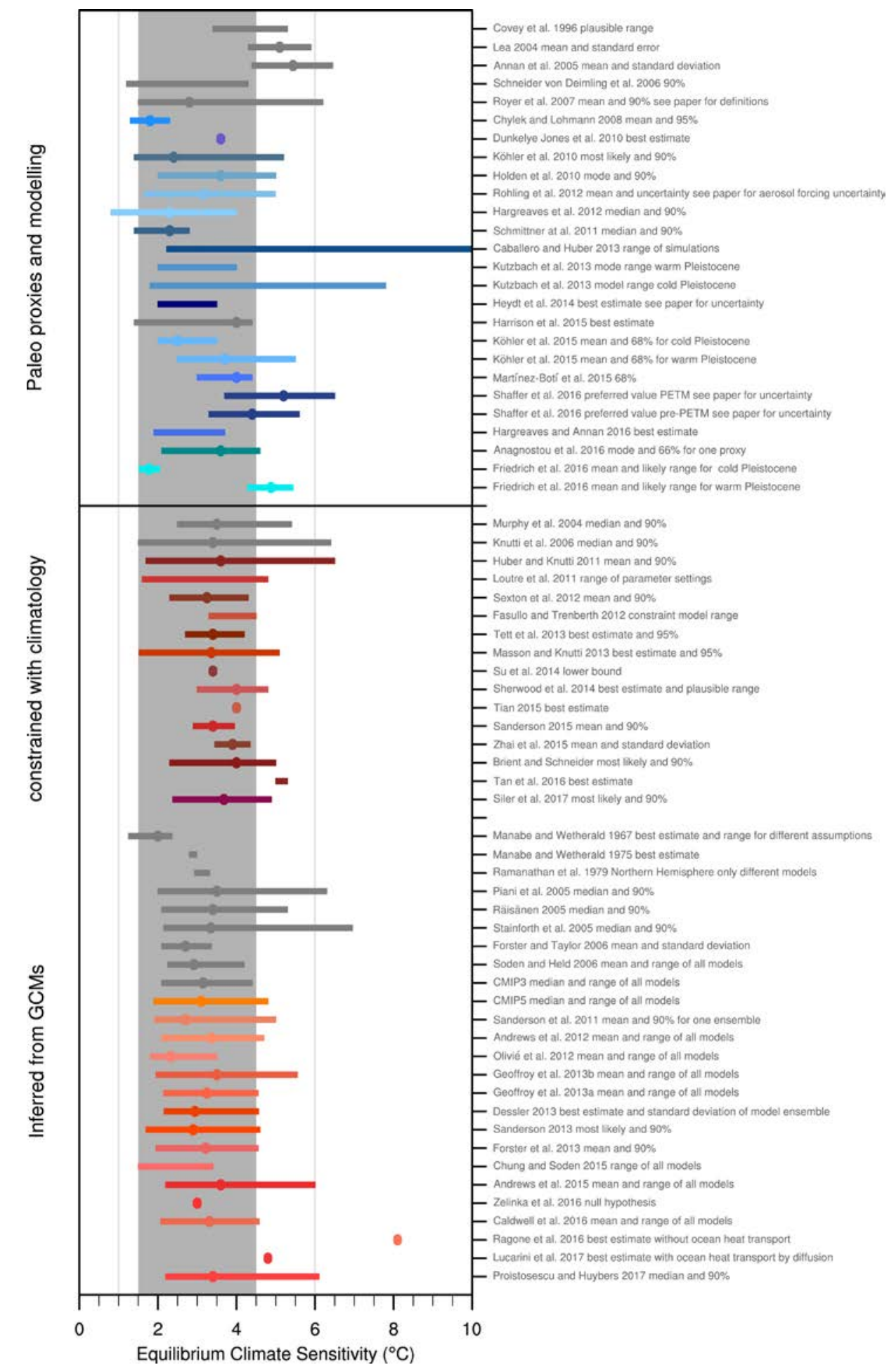

Figure 3: Overview of published best estimates and ranges for equilibrium climate sensitivity constrained by different lines of evidence. Continued from Fig 2. Supplementary figure S1 provides a combination of Figures 2 and 3. 


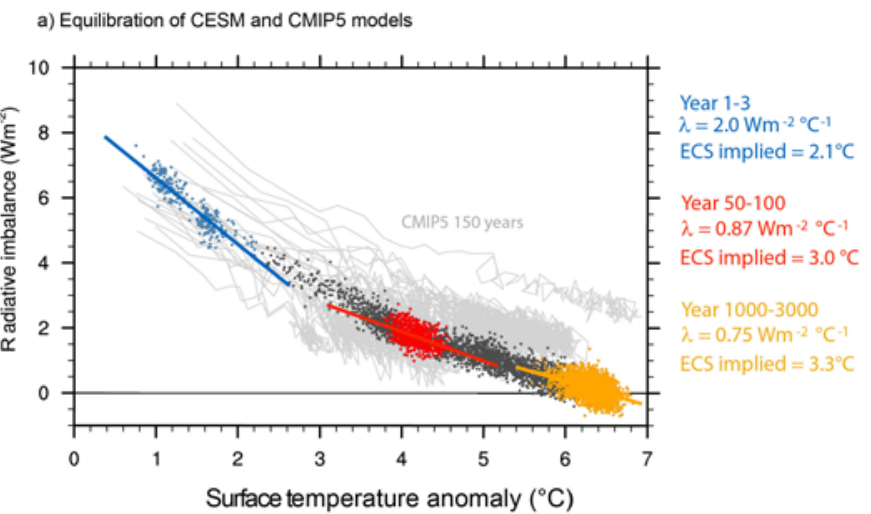

b) Processes influencing the evolution of climate feedbacks

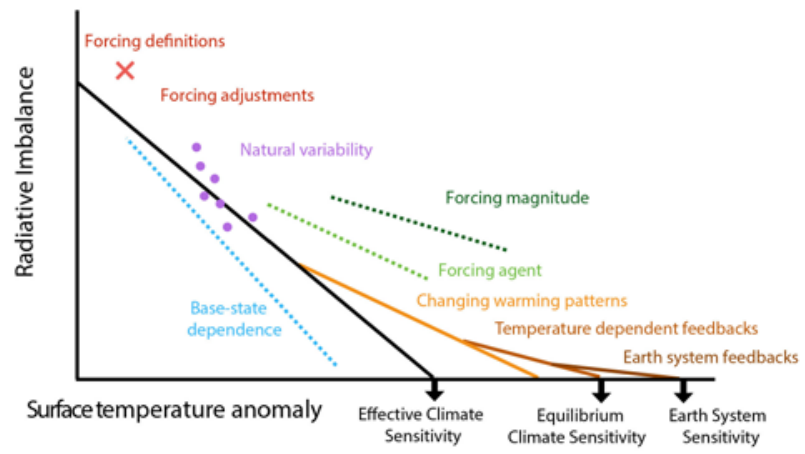

Figure 4: Illustration of feedbacks changing in result to various boundary conditions. a) Top of atmosphere radiative imbalance as a function of global mean surface temperature (annual mean values) for CESM (dark gray and different time scales highlighted in colors) and CMIP5 models (light gray), illustrating the change in the global feedback over different time periods and the implications on equilibrium climate sensitivity. b) Conceptual illustration of the different processes, boundary conditions and forcings that can cause such changes in the global feedback parameter and climate sensitivity (slope and intercept of the line, respectively). 

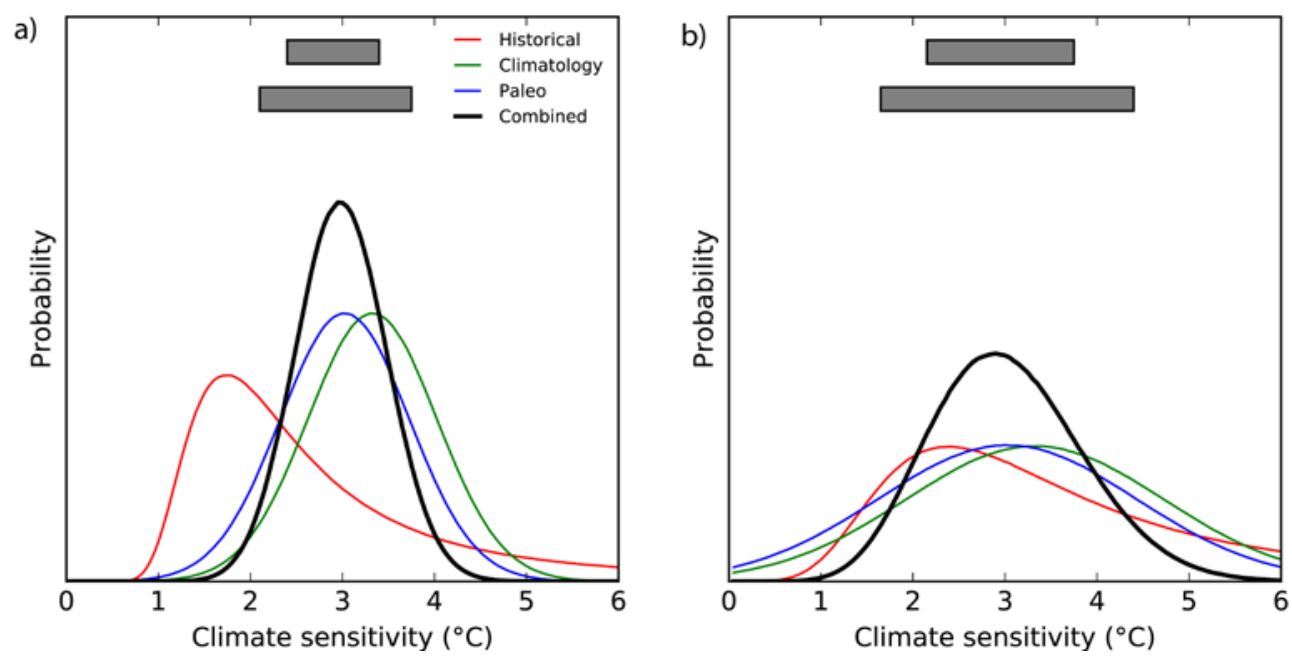

Figure 5: Illustrative example of combining multiple constraints for climate sensitivity. Overall PDFs are the products of three PDFs based on the historical warming, climatological constraints on mostly GCMs, and paleoclimate. Grey ranges at the top indicate a 'likely' (66\%) and 'very likely' (90\%) combined range. a) Constraint based on an optimistic interpretation of uncertainty ranges and assuming full independence, and b) on inflated ranges to account for structural uncertainties, and with historical estimates inflated and scaled up to account for observation biases, and feedbacks varying from historical to future and across forcings. See Methods for details. 